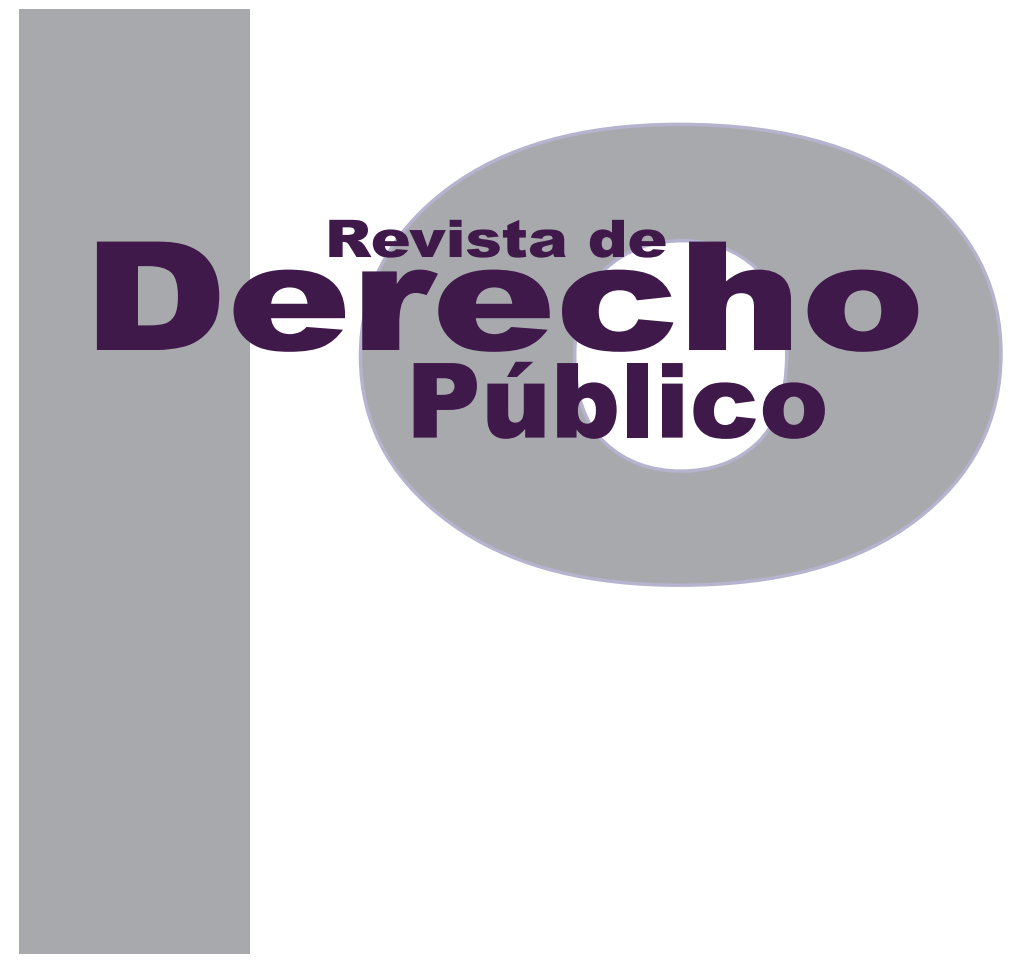

\title{
CONSTITUCIONALISMO, PLURALISMO JURÍDICO Y DERECHOS DE LAS MUJERES INDÍGENAS
}

\author{
Rocío VilLANUEVA FLORES
}

Artículo de reflexión

Universidad de los Andes

Facultad de Derecho

Revista de Derecho Público N. ${ }^{\circ} 32$

Enero - Junio de 2014. ISSN 1909-7778 


\title{
Constitucionalismo, pluralismo jurídico y derechos de las mujeres indígenas
}

\section{Resumen}

El artículo analiza los desafíos que la protección de los derechos individuales de las mujeres indígenas plantea al constitucionalismo latinoamericano y al pluralismo jurídico. Varias de las constituciones de la región reconocen derechos colectivos a las comunidades indígenas. De acuerdo con las investigaciones sobre la vida de las mujeres indígenas, existen en América Latina prácticas culturales que son abiertamente contrarias a sus derechos fundamentales. El artículo postula que en el Estado constitucional de derecho, los derechos individuales de las mujeres indígenas a la dignidad, libertad e igualdad deben prevalecer sobre el derecho colectivo de las comunidades indígenas a conservar sus normas propias y a vivir en concordancia con ellas.

Palabras clave: Estado constitucional, pluralismo jurídico, derechos colectivos de las comunidades indígenas, derechos individuales de las mujeres indígenas, diálogo intercultural.

\section{Constitutionalism, legal pluralism and indigenous women's rights}

\begin{abstract}
The article analyzes the challenges that Latin American constitutionalism and legal pluralism face regarding the protection of indigenous women's rights. Many of the Latin American constitutions protect collective rights of indigenous peoples. According to the research on the lives of Latin American indigenous women, there are cultural practices that do not respect their fundamental rights. This article argues that according to the constitutional rule of law, indigenous women's rights to dignity, freedom and equality should stand before the collective rights of indigenous peoples to preserve their culture.
\end{abstract}

Keywords: Constitutional rule of law, legal pluralism, collective rights of indigenous peoples, indigenous women's rights, intercultural dialogue.

\section{Constitucionalismo, pluralismo jurídico e direitos das mulheres indígenas}

\section{Resumo}

0 artigo analisa os desafios que a proteção dos direitos individuais das mulheres indígenas apresenta ao constitucionalismo latino-americano e ao pluralismo jurídico. Várias das constituições da região reconhecem direitos coletivos às comunidades indígenas. De acordo com as pesquisas sobre a vida das mulheres indígenas, existem na América Latina práticas culturais que são abertamente contrárias a seus direitos fundamentais. 0 artigo postula que no Estado constitucional de direito, os direitos individuais das mulheres indígenas à dignidade, liberdade e igualdade devem prevalecer sobre o direito coletivo das comunidades indígenas a conservar suas próprias normas e a viver em concordância com elas.

Palavras-chave: Estado constitucional, pluralismo jurídico, direitos coletivos das comunidades indígenas, direitos individuais das mulheres indígenas, diálogo intercultural. 


\section{SUMARIO}

Introducción - I. LA CONSTITUCIÓN DEL ESTADO CONSTITUCIONAL Y LA FUERZA EXPANSIVA DE LOS DERECHOS FUNDAMENTALES - II. LOS ÓRDENES NORMATIVOS INDÍGENAS EN LAS CONSTITUCIONES LATINOAMERICANAS - III. EL PLURALISMO JURÍDICO EN EL ESTADO CONSTITUCIONAL - A. El pluralismo jurídico fuerte y el pluralismo jurídico débil - B. ¿Puede toda forma de control social ser calificada como Derecho? - C. Las prácticas de los órdenes normativos indígenas - D. La costumbre jurídica y las prácticas indígenas como fuentes del Derecho - IV. IMPORTANCIA DE LA PREOCUPACIÓN POR LA SITUACIÓN DE LAS MUJERES EN LAS COMUNIDADES INDÍGENAS - A. Prácticas indígenas relativas a la vida de las mujeres - B. Derechos colectivos, diálogo intercultural y derechos de las mujeres - Bibliografía. 


\title{
Constitucionalismo, pluralismo jurídico y derechos de las mujeres indígenas ${ }^{1}$
}

\author{
Rocío Villanueva Flores ${ }^{2}$
}

Introducción

En América Latina estamos viviendo un proceso de transformación de nuestros ordenamientos jurídicos, como consecuencia de la adhesión a un nuevo modelo de organización jurídico político denominado "constitucionalismo" o "neoconstitucionalismo"3, cuyo correlato en

1 Cómo citar este artículo: Villanueva Flores, R. (Junio, 2014). Constitucionalismo, pluralismo jurídico y derechos de las mujeres indígenas. Revista de Derecho Público, 32.

2 Abogada por la Pontificia Universidad Católica del Perú. Diploma de Especialista en Derechos Humanos por el Instituto de Derechos Humanos de la Universidad Complutense de Madrid. Doctora en Derecho por la Universidad de Castilla La Mancha. Profesora principal de la Facultad de Derecho de la Pontificia Universidad Católica del Perú y directora académica de Relaciones Institucionales de la misma universidad. Ex viceministra de la Mujer y ex defensora adjunta para los Derechos de la Mujer de la Defensoría del Pueblo del Perú. Ha dirigido la Escuela del Ministerio Público y ha tenido a su cargo el Observatorio de Criminalidad de esa institución. Correo: mrvillan@pucp.edu.pe

Conviene distinguir el "constitucionalismo" como fenómeno o hecho social del constitucionalismo como concepción del derecho, que supone un nuevo paradigma en el pensamiento jurídico. Véase ATIENZA, Manuel. Argumentación y Constitución [en línea], p. 3. Disponible en: http://www2.uah.es/filder/manuel_atienza.pdf. Quienes defienden el constitucionalismo como concepción del derecho cuestionan la estrechez del modelo positivista para dar cuenta del constitucionalismo. Una excelente síntesis de esta discusión se encuentra en AGUILÓ REGLA, Josep. Positivismo y postpositivismo. Dos paradigmas jurídicos en pocas palabras. En: LINFANTE VIDAL, Isabel. Interpretación jurídica y teoría del Derecho. Lima: Palestra, 2010, p. 18 y ss. la teoría jurídica ha llevado al debate sobre el cambio del paradigma positivista (legalista) al postpositivista (constitucionalista) ${ }^{4}$.

En el marco de este proceso de transformación de los ordenamientos jurídicos, cuyo grado de avance difiere de país en país, se están dando interesantes discusiones jurídicas sobre la justicia indígena. Si bien este proceso de transformación de los ordenamientos jurídicos no es lineal y está muy lejos de estar consolidado en la región ${ }^{5}$, tengo la impresión de que parte de

4 Ibíd., p. 20-22.

5 Guastini afirma que la constitucionalización del ordenamiento jurídico es un proceso de transformación, al final del cual el ordenamiento está "impregnado" por las normas constitucionales. Este autor italiano propone siete condiciones que se deben cumplir para que tales ordenamientos puedan considerarse constitucionalizados. Como la constitucionalización es una cuestión de grado (no de todo o nada), un ordenamiento estará más constitucionalizado en la medida en que vaya cumpliendo esas condiciones. Tales condiciones son las siguientes: 1) Que el ordenamiento jurídico cuente con una Constitución rígida, 2) Que haya un control sobre la conformidad de las leyes con la Constitución, 3) Que la Constitución tenga fuerza vinculante, 4) Que la Constitución se sobreinterprete, 5) Que las normas constitucionales tengan aplicación directa, 6) Que se lleve a cabo una interpretación conforme de las leyes y 7) Que la Constitución influya en las relaciones políticas. En su opinión, solo las dos primeras son condiciones necesarias, mientras que cada una de las otras son más bien una condición suficiente de un grado distinto de constitucionalización. Véase GUASTINI, 
las discusiones y afirmaciones sobre la justicia indígena y sus prácticas no toman en cuenta los rasgos que definen el modelo de Estado constitucional. De lo contrario, no se afirmaría que el derecho a la igualdad entre hombres y mujeres debe entenderse siempre en cada contexto cultural $^{6}$ o que en caso de ponderación entre los derechos de las comunidades indígenas y los derechos fundamentales, los primeros tienen un peso mayor prima facie ${ }^{7}$.

Por ello, el propósito de este artículo es plantear algunas reflexiones sobre el derecho de las comunidades indígenas a conservar y vivir de acuerdo con sus propias normas y prácticas, en el marco del Estado constitucional de derecho, poniendo énfasis en la situación de las mujeres en tales comunidades.

\section{LA CONSTITUCIÓN DEL ESTADO CONSTITUCIONAL Y LA FUERZA EXPANSIVA DE LOS DERECHOS FUNDAMENTALES}

Hace varios años Josep Aguiló escribió un artículo sobre el papel de la Constitución como fuen-

Riccardo. La constitucionalización del ordenamiento jurídico: el caso italiano. En: Miguel CARBONELL (ed.). Neoconstitucionalismo(s). Madrid: Editorial Trotta, 2003, p. 49-73.

6 GRIJALBA, Agustín. El estado plurinacional e intercultural en la Constitución ecuatoriana de 2008. En: YRIGOYEN FAJARDO, Raquel (editora). Pueblos indígenas. Constituciones y reformas políticas en América Latina. Lima: Instituto Internacional de Derecho y Sociedad, 2010, p. 158.

7 Corte Constitucional de Colombia, sentencia T-514/09, fundamento 5.4 . te del derecho en los Estados constitucionales ${ }^{8}$. De ese trabajo me interesa rescatar dos ideas que, en mi opinión, son centrales para el debate sobre los límites de las prácticas indígenas en el marco del constitucionalismo. La primera de ellas es la relativa a la dimensión valorativa de la Constitución y la segunda está referida a la fuerza expansiva de los derechos constitucionales.

Según Aguiló las constituciones tienen dos dimensiones: la dimensión constitutiva y la dimensión valorativa. La primera dimensión se refiere a todas aquellas realidades institucionales creadas por las constituciones (como los parlamentos, tribunales constitucionales, etc.), pues la acción política y jurídica del Estado (órganos y procedimientos) no es natural sino institucional. El mencionado autor plantea que, además de esa dimensión, las constituciones del constitucionalismo tienen una dimensión valorativa pues también reconocen estados de cosas como valiosos y, en consecuencia, merecedores de ser protegidos ${ }^{9}$. Dentro de esta segunda dimensión, Aguiló ubica el reconocimiento de "valores y fines que dotan de sentido a las formas de acción política (órganos y procedimientos) creadas por ellas mismas" ${ }^{10}$. Tales valores

8 AGUILÓ, Josep. Sobre la constitución del estado constitucional. En: Doxa, 2001, p. 451-452. En el Perú este artículo ha sido publicado en un libro que recoge cuatro textos del autor: La Constitución del Estado Constitucional. Lima-Bogotá: Palestra-Temis, 2004, p. 15-62. Según Aguiló, para hablar de un Estado constitucional "tiene que haberse consolidado una práctica jurídica y política que permita afirmar que de hecho en torno a la constitución formal se ha producido la estabilización de las conductas jurídicas y políticas de la comunidad en referencia".

$9 \quad$ lbíd., p. 446-447.

10 Ibíd., p. 447. Aguiló es consciente del "tufillo" iusnaturalista de la expresión "reconocimiento de valores y fines", por ello aclara que la usa con la "pretensión de establecer una prioridad interpretativa de aqué- 
y fines, como la libertad o igualdad, afirman el papel regulativo de la Constitución, es decir, de guía de conducta y de imposición de deberes ${ }^{11}$.

Para Aguiló, el sentido de "darse una constitución" es el de fundar o refundar la unidad de una comunidad política asegurando "ciertas formas de acción política y ciertos criterios de legitimidad de las mismas, es decir, ciertos valores que la acción política tiene que respetar y ciertos fines que la acción política y jurídica tiene que perseguir"12. Esos valores y fines se incorporan a la Constitución como principios regulativos de la acción política legítima ${ }^{13}$. Como señala Alexy, la vinculación entre los aspectos formales o procedimentales con los de tipo sustancial permite "tener en cuenta tanto el carácter institucional como el carácter ideal del Derecho" ${ }^{14}$.

Finalmente, Aguiló sostiene que en los Estados constitucionales se ha pasado de interpretar los derechos y principios constitucionales "como exigencias que centralmente imponen límites negativos a la acción política y jurídica legítimas a verlos como el contenido propio de la acción política y jurídica legítimas"15. Ello crea una es-

llos frente a las formas de acción (poder normativo) creadas por la constitución, pero no para abrir una brecha de supraprositividad frente a la constitución formal”. Véase la nota a pie de página 27.

11 Ibíd., p. 449.

12 lbíd., p. 448.

13 Ibíd., p. 451.

14 ALEXY, Robert. Una defensa de la Fórmula de Radbruch. En: Rodolfo Vigo (coord.). La injusticia extrema no es derecho. De Radbruch a Alexy. Buenos Aires: Editorial Fontamara, 2008, p. 375.

15 AGUILÓ REGLA, Josep. Sobre la constitución del estado constitucional, ob. cit., p. 454. pecial relación entre los derechos constitucionales y el orden jurídico, pues se entiende que este último será la concreción de las exigencias normativas derivadas de los derechos constitucionales, siendo tales derechos fuentes centrales para determina qué se debe prohibir, ordenar y sancionar. De este modo, en el Estado constitucional se otorga a los derechos fundamentales una fuerza expansiva fundamental en la determinación del contenido del orden jurídico ${ }^{16}$. Por ello, además de la consistencia normativa entre las reglas (posibilidad de cumplimiento simultáneo) se exige que las normas sean valorativamente coherentes entre sí, lo que significa que deben presentar "una unidad se sentido y/o de propósitos prácticos" ${ }^{17}$, una unidad de contenidos. De esta forma, en el Estado constitucional, el derecho no puede ser concebido solo como el conjunto de normas que organiza el uso legítimo de la fuerza, sino como el conjunto de normas que tiene por finalidad garantizar los derechos constitucionales $^{18}$. La fuerza expansiva de los derechos fundamentales no se limita al contenido del orden jurídico, puesto que hoy en día se

16 Ibíd. p. 454. El Tribunal Constitucional peruano ha señalado que "los derechos fundamentales son efectivamente derechos subjetivos pero también constituyen manifestación de un orden material y objetivo de valores constitucionales en los cuales se sustenta todo el ordenamiento jurídico. Esta última dimensión de los derechos fundamentales se traduce, por un lado, en exigir que las leyes se apliquen conforme a los derechos fundamentales (efecto de irradiación de los derechos en todos los sectores del ordenamiento jurídico) y, por otro, en imponer sobre todos los organismos públicos un deber de tutelar dichos derechos". Véase la STC n. ${ }^{\circ}$ 03343-2007-PA, fundamento 6.

17 AGUILÓ REGLA, Josep. Positivismo y postpositivismo. Dos paradigmas jurídicos en pocas palabras, ob. cit., p. 22.

18 Véase LINFANTE, Isabel. La teoría de Ronald Dworkin: la reconstrucción del derecho a partir de los casos. En: Jueces para la Democracia, 1999, n. ${ }^{\circ} 36$, p. 46. 
entiende que la Constitución moldea las relaciones sociales y tiene también aplicación directa en las relaciones entre particulares ${ }^{19}$.

Los derechos humanos a los que se refiere el paradigma del Estado constitucional son los derechos humanos individuales. Como he afirmado en otro lugar, el problema que se genera en varios ordenamientos jurídicos latinoamericanos es que no solo reconocen derechos constitucionales individuales sino también derechos colectivos a las comunidades indígenas. Esto último, ya sea porque los tribunales constitucionales han interpretado que de acuerdo con la Constitución las comunidades indígenas son sujetos de derechos fundamentales ${ }^{20}$, ya porque los Estados han ratificado el Convenio 169 que reconoce derechos humanos a los pueblos indígenas o porque las constituciones expresamente consagran derechos colectivos.

En América Latina ha sido la Corte Constitucional de Colombia la que ha dado el mayor desarrollo a los derechos de las comunidades indígenas. Según dicha Corte: “(i) las comunidades indígenas son sujetos de derechos fundamentales; (ii) esos derechos no son equivalentes a los derechos individuales de cada uno de sus miembros, ni a la sumatoria de éstos; (iii) los derechos de las comunidades indígenas no son

19 GUASTINI, Riccardo. La constitucionalización del ordenamiento jurídico: el caso italiano, ob. cit., p. 55.

20 Desde 1992, la Corte Constitucional de Colombia se ha referido a "los derechos de las comunidades indígenas" (sentencia T-428/92, fundamento E, 2). En 1993 afirmó que la comunidad indígena había "dejado de ser solamente una realidad fáctica y legal para pasar a ser sujeto de derechos fundamentales" (sentencia T-380/93, fundamento 8). asimilables a los derechos colectivos de otros grupos humanos (...)"21.

\section{LOS ÓRDENES NORMATIVOS INDÍGENAS EN LAS CONSTITUCIONES LATINOAMERICANAS}

Entre los derechos colectivos de las comunidades indígenas se encuentran el derecho que tienen a conservar y vivir de acuerdo con sus normas propias ${ }^{22}$ y el derecho a administrar justicia o a resolver conflictos internos según tales normas propias. Varias constituciones de América Latina han incorporado disposiciones expresas sobre este último derecho. Ese es el caso de las constituciones de Bolivia (artículo 191.I), Colombia (artículo $246^{\circ}$ ), Ecuador (artículo $171^{\circ}$ ), Guatemala (artículo $66^{\circ}$ ), México (artículo $2^{\circ} \mathrm{A}$ II), Nicaragua (artículo $89^{\circ}$ ), Paraguay (artículo $63^{\circ}$ ), Perú (artículo $149^{\circ}$ ) y Venezuela (artículo $\left.260^{\circ}\right)^{23}$.

21 Corte Constitucional de Colombia, sentencias T-380/93, T-903/09 y T-514/09, fundamentos 8,2 y 2 , respectivamente.

22 Convenio 169 de la OIT sobre pueblos indígenas y tribales en países independientes:

Artículo 8.2.- Dichos pueblos deberán tener el derecho de conservar sus costumbres e instituciones propias, siempre que éstas no sean incompatibles con los derechos fundamentales definidos por el sistema jurídico nacional ni con los derechos humanos internacionalmente reconocidos. Siempre que sea necesario, deberán establecerse procedimientos para solucionar los conflictos que puedan surgir en la aplicación de este principio." (Subrayas añadidas).

Artículo 9.1.- En la medida en que ello sea compatible con el sistema jurídico nacional y con los derechos humanos internacionalmente reconocidos, deberán respetarse los métodos a los que los pueblos interesados ocurren tradicionalmente para la represión de los delitos cometidos por sus miembros". (Subrayas añadidas).

23 En los casos de Bolivia, Colombia, Ecuador Perú y Venezuela la justicia indígena es reconocida como una jurisdicción especial. En cambio, en Guatemala el artículo $203^{\circ}$ de la Constitución señala que "la función jurisdiccional se ejerce, con exclusividad absoluta, por la Corte Suprema de Justicia y por los demás tribunales que la ley establezca". 
Los artículos constitucionales sobre justicia indígena suelen establecer que las normas o prácticas tradicionales no deben violar los derechos fundamentales de la persona; y que una ley regulará las formas de coordinación entre la justicia indígena y la justicia ordinaria.

En Venezuela ${ }^{24}$, Ecuador ${ }^{25}$ y Bolivia ${ }^{26}$ se han dictado leyes que contienen algunas reglas de coordinación entre la jurisdicción indígena y ordinaria, aunque el sentido de "coordinación" no es el mismo en ellas. En Colombia, a falta de ley de coordinación, la Corte Constitucional se ha encargado de establecer la competencia y los límites de la jurisdicción indígena, al resolver procesos de tutela en los que los propios indígenas han cuestionado las decisiones de sus autoridades $^{27}$. La jurisprudencia de la Corte Constitucional es, en este tema (y en muchos otros), un referente fundamental en América Latina, aunque, en ocasiones, se discrepe con ella.

En el caso peruano, el Congreso no ha aprobado la ley que debe regular las formas de coordinación entre la jurisdicción indígena y estatal,

24 Ley Orgánica de Pueblos y Comunidades Indígenas, de 8 de diciembre de 2005

25 Ley de Garantías Jurisdiccionales y Control Constitucional, de 21 de septiembre de 2009 .

26 Ley . $^{\circ} 73$, de 29 de diciembre de 2010, Ley de Deslinde Jurisdiccional.

27 Sobre la jurisprudencia de la Corte Constitucional de Colombia en materia de jurisdicción indígena me he ocupado en VILLANUEVA FLORES, Rocío. Derecho a la salud, perspectiva de género y multiculturalismo. Lima: Palestra, 2009, p. 184 y ss., y en Tensiones constitucionales: el derecho a la diversidad cultural vs. los derechos de las víctimas de violencia de género. En: La facultad de administrar justicia de las rondas campesinas. Comentarios sobre el Acuerdo Plenario que reconoce facultades jurisdiccionales a las rondas campesinas. Lima: Instituto de Defensa Legal, 2010, p. 60 y ss. según lo señalado en el artículo $149^{\circ}$ de la Constitución ${ }^{28}$. Sin embargo, la Corte Suprema ha establecido el alcance de la jurisdicción indígena a través de un acuerdo plenario, pero aún es tarea pendiente establecer las reglas de la mencionada coordinación ${ }^{29}$.

La incorporación de los artículos sobre la justicia indígena en las constituciones latinoamericanas ha dado lugar a un proceso de institucionalización de esa justicia, pues, ya sea a través de la legislación o de la jurisprudencia, se han establecido un conjunto de normas y criterios para regularla ${ }^{30}$. Adicionalmente, varias comunidades indígenas cuentan con reglamentos 0 estatutos escritos.

28 Este incumplimiento podría configurar un caso de inconstitucionalidad por omisión legislativa. El Tribunal Constitucional peruano ha establecido cuatro requisitos para que se configure tal situación. En primer lugar, debe tratarse de una obligación constitucional de regulación, categoría en la que se ubican los mandatos constitucionales que establecen encargos directos al legislador. En segundo lugar, la necesidad de legislar debe estar referida a un ámbito específico claramente identificable. En tercer lugar, la omisión normativa supone un lapso transcurrido en exceso entre el momento en que se dicta la Constitución y el momento en que debe cumplirse la obligación de llevar a cabo el desarrollo normativo, para cuya determinación el juez constitucional debe tomar en cuenta la doctrina del plazo razonable y atender a los resultados inconstitucionales que dicha omisión pueda ir ocasionando en el tiempo y que haga cada vez más indispensable la emanación de la norma de desarrollo constitucional. En cuarto lugar, es necesario que la omisión normativa se concrete en verdaderos actos inconstitucionales, que pueden estar representados por violaciones graves y manifiestas de los derechos fundamentales o por la negación absoluta de su goce y disfrute efectivo. Véase la STC 05427-2009 PC, fundamento 6 .

29 Sobre el Acuerdo Plenario n. 1-2009/CJ-116 (Rondas campesinas y derecho penal) me he ocupado en Tensiones constitucionales: el derecho a la diversidad cultural vs. los derechos de las víctimas de violencia de género, ob. cit., p. 53-72.

30 Por ejemplo, en México, en el estado de Puebla se han creado juzgados indígenas como parte del poder judicial, mediante Ley Orgánica del Poder Judicial del Estado, de 30 de diciembre de 2002. Véase MALDONADO, Korinta y TERVEN, Adriana. Los juzgados indígenas de Cuetzalan y Huehuetla. Vigencia y reproducción de los sistemas normativos de los pueblos de la Sierra Norte de Pueblo. Prólogo de François Lartigue. México: CONACYT, CIESAS y CDI, 2008. 
Por otro lado, no queda ninguna duda de que varias constituciones latinoamericanas reconocen como fuente del derecho a las prácticas tradicionales indígenas ${ }^{31}$. Los textos constitucionales utilizan los siguientes términos para referirse a tales prácticas: "principios, valores culturales, normas y procedimientos propios" (Constitución de Bolivia), "propias normas y procedimientos" (artículos $246^{\circ}$ y $260^{\circ}$ de las constituciones coIombiana y venezolana), "tradiciones ancestrales y derecho propio" (artículo $171^{\circ}$ de la Constitución de Ecuador), "formas de vida, costumbres, tradiciones" (Constitución de Guatemala), "propios sistemas normativos" (artículo $2^{\circ} \mathrm{A}$ II de la Constitución de México), “normas consuetudinarias y derecho consuetudinario indígena" (artículo $63^{\circ}$ de la Constitución de Paraguay), "derecho consuetudinario" (artículo $149^{\circ}$ de la Constitución del Perú) o "tradiciones" (artículo $89^{\circ}$ de la Constitución de Nicaragua).

\section{EL PLURALISMO JURÍDICO EN EL ESTADO CONSTITUCIONAL}

\section{A. El pluralismo jurídico fuerte y el pluralismo jurídico débil}

Yrigoyen sostiene que la incorporación de los artículos citados constituye el reconocimiento constitucional del pluralismo jurídico ${ }^{32}$. Según

31 La Corte Constitucional de Colombia ha afirmado que en el espacio de la creación y aplicación del derecho, la autonomía de las comunidades indígenas "comporta una limitación al monopolio de creación del derecho del Congreso (y, excepcionalmente del Ejecutivo)". Véase la sentencia T-514/09 de la Corte Constitucional de Colombia, fundamento 3.3 .

YRIGOYEN FAJARDO, Raquel. A los veinte años del Convenio 169 de la OIT: balance y retos de la implementación de los derechos de los
Merry, el término pluralismo jurídico se empezó a utilizar a partir de los setenta, y sirvió para dar cuenta de la realidad creada por la imposición del derecho colonial (codificado y centralizado) a los pueblos tribales de África, Asia y el Pacífico, cuyos órdenes jurídicos eran no escritos y carecían de estructuras formales para juzgar y sancionar ${ }^{33}$.

El término pluralismo jurídico es usado principalmente por antropólogos y sociólogos para cuestionar el monopolio estatal de la producción jurídica y del uso legítimo de la fuerza ${ }^{34}$. A pesar de que se pueden identificar distintas corrientes (trends) sobre el pluralismo jurídico, todas ellas coinciden en que el derecho (law) es más que el derecho estatal ${ }^{35}$.

En un clásico trabajo sobre pluralismo jurídico, John Griffiths distingue entre el pluralismo jurídi-

pueblos indígenas de Latinoamérica. En: YRIGOYEN FAJARDO, Raquel (ed.). Pueblos indígenas. Constituciones y reformas políticas en América Latina. Lima: Instituto Internacional de Derecho y Sociedad, 2010, p. 16. Cabe señalar que el artículo $1^{\circ}$ de la Constitución boliviana (2009) señala que "Bolivia se constituye en un Estado Unitario Social de Derecho Plurinacional Comunitario, libre, independiente, soberano, democrático, intercultural, descentralizado y con autonomías. Bolivia se funda en la pluralidad y el pluralismo político, económico, jurídico, cultural y lingüístico, dentro del proceso integrador del país".

33 MERRY, Sally Engle. Pluralismo jurídico. En: ARIZA HIGUERA, Libardo y BONILLA MALDONADO, Daniel. Pluralismo jurídico. Bogotá: Siglo del Hombre Editores, Universidad de los Andes, Pontificia Universidad Javeriana, 2007, p. 99 y ss.

34 YRIGOYEN FAJARDO, Raquel. Pautas de coordinación entre el derecho indígena y el derecho estatal, ob. cit., p. 11-12 y BAZÁN SEMINARIO, César. Estado plural de derecho. Bases para una redefinición del concepto Estado de derecho a la luz de la pluralidad jurídica. Lima: Instituto de Defensa Legal, noviembre de 2012, p. 62 y 63.

35 DUPRET, Baudouin. Legal Pluralism, Plurality of Laws, and Legal Practices: Theories, Critiques, and Praxiological Re-specification. In: European Journal of Legal Studies Issue, April 2007, 1, p. 1. En este artículo se describen brevemente las distintas corrientes del pluralismo jurídico. 
co fuerte y el pluralismo jurídico débil. Aunque el mencionado texto fue publicado en 1986 sigue siendo una referencia importante en trabajos recientes sobre la justicia indígena ${ }^{36}$.

Griffiths parte del cuestionamiento al "centralismo legal", que considera un mito en virtud del cual se entiende que el derecho es uniforme, sistemático y está administrado por un conjunto único de instituciones estatales. Añade que en el centralismo legal "los otros órdenes normativos menores -la Iglesia, la familia, las asociaciones voluntarias y las organizaciones económicas- deben estar jerárquicamente subordinados al derecho y a las instituciones del Estado, como de hecho ocurre" 37 .

Griffiths defiende el pluralismo jurídico fuerte, que considera un hecho, una "situación que es moral y ontológicamente excluida por la ideología del centralismo legal - una situación en la que no todo Derecho (law) es de origen estatal y que tampoco está administrado por un único conjunto de instituciones legales estatales (legal state institutions), y en la que el Derecho (law) no es ni sistemático ni uniforme"38. En cambio, según el mencionado autor, el pluralismo jurídico débil se refiere:

36

Véase, por ejemplo, URTEAGA Patricia. Sobre el Acuerdo Plenario n. 1-2009/CJ-116. Una mirada desde la antropología jurídica. En: La facultad jurisdiccional de las rondas campesinas. Comentarios al acuerdo plenario de la Corte Suprema que reconoce facultades jurisdiccionales a las rondas campesinas. Lima: IDL, septiembre de 2010, p. 35; GUEVARA, Armando. Diversidad y complejidad legal. Aproximaciones a la antropología e historia del Derecho. Lima: Fondo Editorial PUCP, 2009 , p. 40 y ss.

37 GRIFFITHS, John. What is legal Pluralism. p. 3. Disponible en: keur. eldoc.ub.rug.nl/FILES/wetenschappers/2/11886/11886.pdf

38 Ibíd., p. 5. en el marco del centralismo legal a un particular sub tipo del fenómeno considerado como Derecho. En este sentido (débil) un sistema legal es plural cuando el soberano (implícitamente) ordena (o la norma fundamental lo valida) diferentes cuerpos de leyes para diferentes grupos en la población. En general, los grupos concernidos son definidos en términos de características tales como etnicidad, religión, nacionalidad o geografía y el pluralismo legal es justificado como una técnica de gobernabilidad (governance) sobre un sustento pragmático ${ }^{39}$.

De acuerdo con Óscar Correas, la expresión pluralismo jurídico da cuenta del hecho de que en casi todos los países latinoamericanos "las relaciones sociales no se conducen conforme con un sólo sistema normativo, al cual sin mayor fundamento llamamos jurídico, sino que a pesar de lo que se quiera, se arreglan y componen conforme a una multitud de sistemas normativos" 40 . Según el citado autor, nos encontramos ante un fenómeno de pluralismo jurídico "en los casos en que el derecho indígena, convive con las normas producidas por el estado hegemónico" 41 o cuando estemos frente a "la coexistencia de normas que reclaman obediencia en un mismo territorio y que pertenecen a sistemas distintos" ${ }^{42}$. De ahí que, según Correas, estaremos también ante un supuesto de pluralismo jurídico "en el caso del sistema

\footnotetext{
39 Ídem.

40 CORREAS, Óscar. Teoría del derecho y antropología jurídica. Un diálogo inconcluso. México: Ediciones Coyoacán, 2010, p. 67.

41 CORREAS, Óscar. Pluralismo jurídico, alternatividad y derecho indígena. México, D. F.: Fontamara, 2003, p. 37.

42 Ibíd., p. 37.
} 
normativo impuesto por Sendero Luminoso en el Perú o las guerrillas colombianas"43.

Como afirma Tamanaha, la noción de pluralismo jurídico debería enmarcarse en una definición previa sobre el derecho ${ }^{44}$, pues de lo contrario hay que considerar como derecho toda expresión de control social ${ }^{45}$. Por otro lado, las reflexiones sobre el pluralismo jurídico deberían tener presente que en el Estado constitucional se debilita el principio de legalidad frente al principio de constitucionalidad ${ }^{46}$, y que ya no se defiende ni el estatalismo ni el legicentrismo ${ }^{47}$.

\section{B. ¿Puede toda forma de control social ser calificada como derecho?}

Habida cuenta de la dimensión valorativa de la Constitución, la noción de unidad de contenidos del derecho cobra una relevancia especial en las discusiones sobre el pluralismo jurídico. Ello porque en el Estado constitucional los sistemas jurídicos no son solo un conjunto de normas vin-

43 Ídem

44 TAMANAHA, Brian Z. An Analytical Map of Social and Scientific Approaches to the Concept of Law. In: Oxford Journal of Legal Studies, Winter 1995, vol. 15, n. $^{\circ} 4$, p. 502.

45 TAMANAHA, Brian Z. La insensatez del concepto científico social del pluralismo jurídico. En: ARIZA HIGUERA, Libardo y BONILLA MALDONADO, Daniel. Pluralismo jurídico. Bogotá: Siglo del Hombre Editores, Universidad de los Andes, Pontificia Universidad Javeriana, 2007, p. 228.

46 De acuerdo con el principio de legalidad el juez debe sujetarse a la ley, mientras que el principio de constitucionalidad obliga a jueces y a legisladores a someterse a las exigencias de la Constitución. Véase CARBONELL, Miguel. El neoconstitucionalismo en su laberinto. En: CARBONELL, Miguel (ed.). Teoría del neoconstitucionalismo. Ensayos escogidos. Madrid: Editorial Trotta, Instituto de Investigaciones Jurídicas, UNAM, 2007, p. 25.

ATIENZA, Manuel. Argumentación y Constitución, ob. cit., p. 4. culadas entre sí por relaciones de consistencia normativa sino también por relaciones de coherencia valorativa ${ }^{48}$.

En mi opinión, el pluralismo jurídico fuerte es incompatible con el Estado constitucional de derecho, porque desconoce el carácter unitario del Estado y la fuerza expansiva de los derechos fundamentales En un Estado constitucional no toda ordenación social puede ser calificada como derecho, por más que tenga "capacidad para crear normas, resolver conflictos, organizar el orden interno" 49 . No niego la heterogeneidad normativa, lo que rechazo es que todo conjunto de normas socialmente existente sea calificado como jurídico.

La insistencia en la posición de que toda forma de control social es derecho trae como consecuencia posturas irrazonables, como admitir que el grupo terrorista Sendero Luminoso aplicó su sistema jurídico. Con ese mismo criterio, podría afirmarse que el esposo violento que asesina a su mujer aplica su sistema jurídico (que incluye la pena de muerte) o que las normas de los credos religiosos tienen la condición de jurídicas. El crimen organizado también impone normas de conducta y formas de solución de los conflictos, pero esa imposición no las convierte en normas jurídicas (por más eficaces que sean).

Concuerdo con Aguiló, quien afirma que:

\footnotetext{
48 AGUILÓ REGLA, Josep. Positivismo y postpositivismo. Dos paradigmas jurídicos en pocas palabras, ob. cit., p. 22.

49 YRIGOYEN FAJARDO, Raquel. Pautas de coordinación entre el derecho indígena y el derecho estatal, ob. cit., p. 27.
} 
una cosa es sostener que los límites de lo jurídico están socialmente determinados, que la norma última de un sistema jurídico, la que establece los criterios últimos de validez, es siempre una regla social (como, por ejemplo, la regla de reconocimiento hartiana) y que, en consecuencia, en la determinación de lo jurídico rige algo parecido al principio de efectividad; y otra muy distinta, es sostener que una fuente de un ordenamiento jurídico se sitúa fuera de los criterios de validez de ese mismo orden ${ }^{50}$.

Por lo tanto, una forma de pluralismo jurídico débil, en virtud de la cual la Constitución reconoce validez jurídica a los órdenes normativos indígenas que respetan los derechos de las personas, es perfectamente compatible con el Estado constitucional de derecho.

50

AGUILÓ, Josep. Teoría general de las fuentes del Derecho (y del orden jurídico). Barcelona: Ariel, 2000, p. 43. Como afirman Manuel ATIENZA y Juan RUIZ MANERO, los juristas dogmáticos no suelen aludir a la noción de "norma maestra", norma básica/fundamental (grundnorm-Kelsen) o regla de reconocimiento (Hart) (de naturaleza extrasistemática o extrajurídica), pues solo se refieren a las normas contenidas en la fuente que ellos identifican como suprema, es decir, la Constitución. Sostienen, además, que la noción de norma básica o regla de reconocimiento es ineludible para responder a la pregunta de por qué la Constitución es la fuente suprema del ordenamiento español (o cuál es la fuente de esa norma suprema) o por qué la Constitución tiene valor normativo, véase, Las piezas del derecho. Teoría de Ios enunciados jurídicos. Barcelona: Ariel Derecho, septiembre 1996, p. 155. La noción de norma básica ha sido intensamente discutida por los teóricos del derecho. Como se sabe, para KELSEN la norma fundamental era una norma hipotética en virtud de la cual "uno debe comportarse conforme a la Constitución", véase Teoría pura del derecho. México D. F.: Editorial Porrúa, $16^{a}$ edición, 2009, p. 209 y ss. Traducción del original en alemán por Roberto J. Vernengo. Para HART, la regla de reconocimiento permite a los particulares y a los funcionarios contar con criterios para identificar algo como derecho, por ello señalaba "cuando alguien afirma seriamente la validez de una determinada regla de derecho, por ejemplo, una ley, usa una regla de reconocimiento que acepta como adecuada para identificar el derecho (...) ocurre que esta regla de reconocimiento, en términos de la cual aprecia la validez de una ley particular, no solamente es aceptada por él, sino que es la regla de reconocimiento efectivamente aceptada y empleada en el funcionamiento general del sistema", véase El concepto derecho. Genaro R. Carrió (trad.). México, D. F.: Editora Nacional, 1980, p. 135.

\section{Las prácticas de los órdenes normativos indígenas}

Merry señala que estudiosos de sociedades coIoniales han cuestionado el uso de la expresión derecho consuetudinario para dar cuenta del derecho precolonial. Aunque ese derecho era oral y derivaba de fuentes externas al poder coIonial, todo indica que la idea de una costumbre estable fue más bien un mito de la era colonial, y que la propia idea de derecho consuetudinario fue producto del encuentro colonial ${ }^{51}$. El hecho de que no se tratara de un derecho consuetudinario ha llevado a los estudiosos del pluralismo jurídico a utilizar distintas denominaciones para las formas no estatales de ordenamiento social: ordenamiento nativo, derecho nativo, derecho popular, justicia privada, campo social semiautónomo, etc. ${ }^{52}$. Sin duda, como sostiene Merry, la dificultad para encontrar un término para el

51 MERRY, Sally Engle. Pluralismo jurídico, ob. cit., p. 101. Más recientemente, se ha cuestionado el uso de los términos "usos y costumbres" o "derecho consuetudinario", por considerar que la justicia indígena no está subordinada al derecho estatal y porque las comunidades indígenas cuentan con sistemas legales, con sistemas jurídicos indígenas. Véase CUMES, Aura Estela. Mujeres indígenas, poder y justicia: de guardianas a autoridades en la construcción de culturas y cosmovisiones. En: LANG, Miriam y KUCIA, Anna (comp.). Mujeres indígenas y justicia ancestral. Quito: UNIFEM Región Andina, mayo 2009, p. 43 y TIBÁN, Lourdes. Desafíos en la construcción de un Estado plurinacional. En: LANG, Miriam y KUCIA, Anna (comp.). Mujeres indígenas y justicia ancestral, ob. cit., p. 35. También se ha cuestionado el término "justicia comunitaria" porque ni en quechua ni en aymara habría un término cuyo significado equivalga al de "justicia" en castellano, véase TICONA COLQUE, Valentín. Políticas públicas del Gobierno boliviano. En: LANG, Miriam y KUCIA, Anna (comp.). Mujeres indígenas y justicia ancestral, ob. cit., p. 51. A pesar de estos cuestionamientos, la Corte Constitucional de Colombia, cuya jurisprudencia es la más avanzada en materia indígena, utiliza la expresión "costumbre indígena", véase la sentencia T-903/09, fundamento 3.3. El término "costumbres propias" también es usado por el Tribunal Constitucional peruano en una reciente sentencia, véase la STC 01126-2011-HC, fundamento 23.

MERRY, Sally Engle. Pluralismo jurídico, ob. cit., p. 103 y ss. 
derecho no estatal tiene que ver con la gran variedad de los órdenes no estatales.

Por lo tanto, he escogido utilizar los términos "órdenes normativos indígenas" y "prácticas indígenas" en lugar de derecho consuetudinario y costumbre indígena. El uso del plural contribuye a enfatizar que pueden existir tantos "órdenes normativos" como comunidades indígenas.

Cuando se estudia el contenido de los órdenes normativos indígenas se advierte que no todas las prácticas son precoloniales ${ }^{53}$. Por el contrario, en ellos se identifican prácticas traídas por los españoles (como el azote ${ }^{54}$ ), otras que han incorporado elementos de la religión católica ${ }^{55}$

53 GUAMÁ, Lucy; PANCHO, Avelina y REY, Elena. Antigua era más duro: hablan las mujeres indígenas de Antioquia. Colección Autonomía Indígena 3. Bogotá: Centro de Cooperación al Indígena (Cecoin) y Organización Indígena de Antioquia (OIA), 2009, p. 22.

54 NOSTAS ARDAYA, Mercedes y SANABRIA SALMÓN, Carmen Elena (coinvestigadoras). Detrás del cristal con que se mira: órdenes normativos e interlegalidad. Mujeres quechuas, aymaras, sirionó, trinitarias, chimane, chiquitanas y ayoreas. La Paz: Coordinadora de la Mujer, 2009, p. 93. En este trabajo se afirma que el castigo físico del azote se instituyó durante las misiones. Por su parte, Esther SÁNCHEZ BOTERO sostiene que el fuete "fue incorporado por imposición de los españoles y en un proceso de traducción se le acomodó el concepto propio del rayo", véase Derechos propios. Ejercicio de la jurisdicción especial indígena en Colombia. Segunda edición. Bogotá: Procuraduría General de la Nación, Instituto de Estudios del Ministerio Público, 2007, p. 193.

55 NOSTAS ARDAYA, Mercedes y SANABRIA SALMÓN, Carmen Elena (coinvestigadoras). Detrás del cristal con que se mira: órdenes normativos e interlegalidad. Mujeres quechuas, aymaras, sirionó, trinitarias, chimane, chiquitanas y ayoreas, ob. cit., p. 36,47 y 60 . Por ello se habla de un sincretismo entre catolicismo y cosmovisión indígena, como en el caso de los pueblos mojeño-trinitario, chiquitano y chimane en Bolivia. El sincretismo se manifiesta en nociones sobre la culpa, la obediencia, el arrepentimiento o en la asociación falta/pecado. En el pueblo chiquitano los mandatos de obediencia conyugal femenina, fidelidad y los preceptos de la moral sexual (por ejemplo, la virginidad de las mujeres previa al matrimonio) se explican por la influencia de la religión católica desde la colonia, ibíd., p. 86 y 88 . Al respecto, véase también HERNÁNDEZ CASTILLO, Aída. El derecho positivo y la costumbre jurídica: las mujeres indígenas de Chiapas y sus luchas por el acceso a la justicia. En: TORRES FALCÓN, Marta. Violencia contra las mujeres en contextos urbanos y rurales. México: El Colegio de México, Programa Interdisciplinario de Estudios de la Mujer, 2003, p. 21. y también aquellas influenciadas por el discurso evangélico ${ }^{56}$. Los órdenes normativos indígenas también están influenciados por el sistema jurídico estatal así como por el entorno regional y global. Por eso, en algunas de las investigaciones realizadas por antropólogas latinoamericanas se emplea el término "interlegalidad" 57 para dar cuenta de esta compleja realidad normativa. Este vocablo también se utiliza para contrarrestar una visión esencialista de los órdenes normativos de las comunidades indígenas, que los presenta como el resultado de un pasado incontaminado, pues tal visión no se condice con la realidad. Para Orellana es difícil hablar de sistemas jurídicos indígenas pues más bien se trata de "órdenes amalgamados, mezclados o entrecruzados, superpuestos (...). Tan porosos que nos obligan a pensar en que lo jurídico y los niveles jurídicos son escenario de interlegalidad e interderecho" 58 .

56 PEQUEÑO, Andrea. Violencia de género y mecanismos de resolución comunitaria en comunidades indígenas de la sierra ecuatoriana. En: LANG, Miriam y KUCIA, Anna (comp.). Mujeres indígenas y justicia ancestral, ob. cit., p. 83; ZAPETA, José Ángel. Valores, principios y situación de la justicia maya en Guatemala. En: LANG, Miriam y KUCIA, Anna (comp.). Mujeres indígenas y justicia ancestral, ob. cit., p. 199.

57 NOSTAS ARDAYA, Mercedes y SANABRIA SALMÓN, Carmen Elena (coinvestigadoras). Detrás del cristal con que se mira: órdenes normativos e interlegalidad. Mujeres quechuas, aymaras, sirionó, trinitarias, chimane, chiquitanas y ayoreas, ob. cit., p. 10 y 112. Véase también CHENAUT, Victoria. Género y justicia en la antropología jurídica en México. En: Papeles de Trabajo n. ${ }^{\circ} 15,2007$, p. 49 y HERNÁNDEZ CASTILLO, Rosalva Aída. Por los entrecruces del género, la justicia y la legalidad en tierras indígenas. En: Desacatos, enero-abril de 2007 , n. ${ }^{\circ} 023$, p. 325.

58 ORELLANA H., René. Derecho: ¿qué eres? ¿dónde estás? Borrador al 29 de mayo de 2001, p. 24. El propio Santos ha criticado la definición del pluralismo jurídico que da cuenta de la coexistencia, en un mismo espacio geopolítico, de dos o más órdenes jurídicos autónomos y geográficamente segregados, véase SANTOS, Boaventura de Sousa. The Law of the Oppressed: The Construction and Reproduction of Legality in Pasargada. In: Law and Society Review, Autumn 1977, vol. 12, n. ${ }^{\circ}$ 1, p. 236. En otro texto este autor señala que la pluralidad jurídica "lejos de ser un residuo de los tiempos premodernos de los países que no han completado aún el proceso de 'modernización', es con- 
Como se ha señalado, las mencionadas investigaciones de antropólogas latinoamericanas dan cuenta de una visión no idealizada, estática o aislada de los órdenes normativos indígenas. Por el contrario, dichos órdenes son presentados como conjuntos de nomas "dinámicas y flexibles", como construcciones sociales en contextos de relaciones de poder, que interactúan fuertemente con el sistema jurídico estatal ${ }^{59}$.

La influencia de las normas religiosas o legales en el contenido de los órdenes normativos indígenas trae como consecuencia que, en ocasiones, haya dificultad para establecer qué prácticas son efectivamente tradicionales ${ }^{60}$ y cuáles rigen $^{61}$.

stitutiva del carácter desigual, dispar y excluyente de dicho proceso, y por esta razón está destinada a ser reinventada recurrentemente y reproducida a medida que la 'modernización' se desenvuelve", véase La globalización del derecho. Los nuevos caminos de la regulación y la emancipación. Bogotá: Facultad de Derecho, Ciencias Políticas y Sociales de la Universidad Nacional de Colombia -ILSA, 1998, p. 149.

59 NOSTAS ARDAYA, Mercedes y SANABRIA SALMÓN, Carmen Elena (coinvestigadoras). Detrás del cristal con que se mira: órdenes normativos e interlegalidad. Mujeres quechuas, aymaras, sirionó, trinitarias, chimane, chiquitanas y ayoreas, ob. cit., p. 85 y 131. En el mismo sentido véase HERNÁNDEZ CASTILLO, Aída. El derecho positivo y la costumbre jurídica: las mujeres indígenas de Chiapas y sus luchas por el acceso a la justicia, ob. cit., p. 21. Véase también ORELLANA H, René. Derecho: ¿qué eres? ¿dónde estás?, ob. cit., p. 15 y 17.

60 CUMES, Aura Estela. Mujeres indígenas, poder y justicia: de guardianas a autoridades en la construcción de culturas y cosmovisiones, ob. cit., p. 43; BATZIBAL, Juana. Conflictos por herencias de mujeres en la justicia ancestral. En: LANG, Miriam y KUCIA, Anna (comp.). Mujeres indígenas y justicia ancestral, ob. cit., p. 195; y BERNARDO SANTOS, Roselia. Promoción de la participación de las mujeres en la justicia indígena en Oaxaca. En: LANG, Miriam y KUCIA, Anna (comp.). Mujeres indígenas y justicia ancestral, ob. cit., p. 218.

61 Mujeres indígenas y justicia ancestral, ob. cit., p. 237 y GUAMÁ, Lucy; PANCHO, Avelina y REY, Elena. Antigua era más duro: hablan las mujeres indígenas de Antioquia, ob. cit., p. 15. Sobre la dificultad de reconocer la "tradición", véase HERNÁNDEZ CASTILLO, Aída. El derecho positivo y la costumbre jurídica: las mujeres indígenas de Chiapas y sus luchas por el acceso a la justicia, ob. cit., p. 30-35. Según Collier, cuando los estudios históricos más ricos sobre los sistemas jurídicos no occidentales provenían de África, los historiadores revelaron "que muchas de las supuestas normas tradicionales puestas en vigor por

\section{La costumbre jurídica y las prácticas indígenas como fuentes del derecho}

La complejidad de la realidad normativa indígena y las exigencias del Estado constitucional obligan a preguntarnos cuándo una práctica indígena puede ser considerada fuente del derecho en el Estado constitucional.

Por fuentes del derecho hay que entender aquellos “hechos y actos (procedimientos) a los que el orden jurídico atribuye la virtualidad (imputa la consecuencia) de crear normas jurídicas generales"62. El problema de las fuentes del derecho, el problema del origen de las normas jurídicas, es un problema interno al orden jurídi$\mathrm{co}^{63}$. En un sistema jurídico serán normas jurídicas las contenidas en la respectiva Constitución

los tribunales consuetudinarios, eran invenciones recientes o apropiaciones selectivas de costumbres pasadas", véase COLLIER, Jane F. Problemas teórico-metodológicos en la antropología jurídica. En: $\mathrm{CHE}$ NAUT, Victoria y SIERRA, María Teresa (coords.). Pueblos indígenas ante el Derecho. México: Centro de Investigaciones y Estudios Superiores en Antropología Social - Centro Francés de Estudios Mexicanos y Centroamericanos, 1995, p. 64. Uno de esos casos era la invención de un matrimonio "tradicional" (que incluía el pago de una dote muy importante en lugar de pequeños regalos) en zonas urbanas del cinturón de cobre de Zambia durante y después de la Gran Depresión (1930). Esta práctica privó a las mujeres de libertades y poderes de los que sus abuelas gozaron.

62 AGUILÓ, Josep. Teoría general de las fuentes del Derecho (y del orden jurídico), ob. cit., p. 49 y 87 . Este autor señala que parte de la definición de fuentes del derecho de Norberto BOBBIO, contenida en su libro: Teoría General del Derecho. Bogotá: Temis, 1987, p. 158. Además, afirma que no pretende que la clasificación entre fuentes acto y fuentes hecho sea exhaustiva y excluyente. Por ello defiende que algunas fuentes solo se explican como una combinación de hechos y actos, y otras no serán ni un cosa ni otra, Ibíd., p. 64. El mencionado libro de Bobbio fue publicado también por la Editorial Debate, Madrid, 1999. La definición de fuentes se encuentra en la página 170: "fuentes del derecho son aquellos hechos o aquellos actos de los cuales el ordenamiento jurídico hace depender la producción de normas jurídicas".

63 AGUILÓ, Josep. Teoría general de las fuentes del Derecho (y del orden jurídico), ob. cit., p. 40. 
y las que se derivan de las fuentes reconocidas o instituidas en ella ${ }^{64}$.

Aunque existe un amplio consenso en que la costumbre es fuente del derecho, lo cierto es que lo que la teoría jurídica estándar ha denominado "costumbre jurídica" no ha incluido al conjunto de prácticas, normas o procedimientos indígenas. Sin embargo, como las prácticas indígenas son un tipo de fuente que surge de hechos, podría enfrentar similares dificultades a las que plantea la calificación de una costumbre como jurídica ${ }^{65}$.

La costumbre jurídica es, según Aguiló, el ejemplo paradigmático de fuente-hecho ${ }^{66}$. Guibourg define la costumbre como fuente del derecho de la siguiente manera:

Cuando un individuo repite un mismo modelo de conducta frente a circunstancias semejantes, decimos que tal modelo de conducta constituye en él un hábito. Cuando un grupo o comunidad de individuos comparte el mismo hábito a lo largo del tiempo, nos sentimos inclinados a aceptar la existencia de una costumbre. Cuando una costumbre provoca que los intereses de las personas se adecuen a ella, de modo tal que las conductas divergentes lesionan expectativas y generan quejas, nos parece razonable hablar de una norma consuetudinaria. Cuando esta norma es efectivamente reconocida por los jueces ${ }^{67} \mathrm{u}$ otros órganos del poder coactivo comunitario como fundamento de sus decisiones, ya no tenemos duda alguna: nos hallamos ante una norma jurídica consuetudinaria ${ }^{68}$.

Según Guibourg, para calificar a una costumbre como jurídica deben darse algunos rasgos. En primer lugar, una dimensión temporal y criterios que permitan establecer que se trata de una conducta repetida. En segundo lugar, la costumbre, al ser una actitud colectiva, exige una pluralidad de sujetos. En tercer lugar, debe existir cierto consenso acerca de la exigibilidad u obligatoriedad de la conducta conforme con la costumbre (opinio necessitatis), aunque haya que admitir que no todas las personas de la comunidad de referencia "participan de la misma actitud de

64 Parafraseo una definición propuesta por Manuel ATIENZA y Juan RUIZ MANERO a propósito de la aclaración que estos autores realizan sobre la regla de reconocimiento como criterio de identificación de las normas del sistema jurídico español. Sostienen que la regla de reconocimiento del sistema jurídico español actual tiene como eje central la aceptación de la Constitución de 1978, su fuente suprema, véase Las piezas del derecho. Teoría de los enunciados jurídicos, ob. cit., p. 154.

65 Aguiló se refiere a la ambigüedad antecedente/consecuente en el tema de las fuentes, que alude a la distinción entre la fuente productora del derecho (o modos de producir normas jurídicas) y norma producida (o formas de manifestación de la producción jurídica). Propone abandonar lo que denomina "esencialismo lingüístico", pues para estudiar, por ejemplo, la ley, hay que estudiar qué hay que hacer para dictar una ley. De la misma forma, estudiar la costumbre supone estudiar aquello que da lugar a una costumbre y las consecuencias que se derivan de que se haya producido una costumbre, véase AGUILÓ, Josep. Teoría general de las fuentes del Derecho (y del orden jurídico), ob. cit., p. 47.

66 Ibíd., p. 87.
67 Para AGUILÓ no se trata de que la costumbre sea jurídica porque los jueces la aplican, la cuestión es determinar cuándo un juez tiene el deber de reconocer que una regla social es una práctica jurídica, ibíd., p. 93.

68 GUIBOURG, Ricardo. Fuentes del Derecho. En: GARZÓN VALDÉS, Ernesto y LAPORTA, Francisco (eds.). El derecho y la justicia. Madrid: Editorial Trotta, Consejo Superior de Investigaciones Científicas, 1996, p. 181. Tradicionalmente, las costumbres han sido divididas en tres tipos, en función de su relación con la ley: praeter legem, secundum legem y contra legem. En el primer caso, la costumbre llena un vacío de la ley. En el segundo caso, el texto expreso de la ley remite a la costumbre. En el tercer caso, se trata de normas consuetudinarias que van en contra de la ley, a las que no se les reconoce validez jurídica, véase RUBIO CORREA, Marcial. El sistema jurídico. Introducción al Derecho. Sexta edición corregida y aumentada. Colección de textos jurídicos de la Pontificia Universidad Católica del Perú. Lima: Fondo Editorial, 1993, p. 201. 
exigibilidad ni, cuando lo hacen, experimentan tal sentimiento con idéntica intensidad" ${ }^{69}$.

Sin embargo, para Aguiló "junto al usus y la opinio hace falta incluir un juicio de relevancia jurídica fundado en la idea de coherencia"70 para calificar una costumbre como jurídica. En consecuencia, las costumbres jurídicas deben ser coherentes con los principios y valores que protege el derecho ${ }^{71}$ pues, como se ha afirmado anteriormente, este aspira a la unidad de contenidos.

La Corte Constitucional de Colombia ha sostenido que la costumbre indígena no es idéntica a la costumbre estudiada tradicionalmente como fuente del derecho (que supone la repetición inveterada de una práctica social específica), pues las prácticas regulativas de buena parte de las comunidades indígenas se encuentran en estado de reconstrucción desde la expedición de la Constitución de 1991, y pueden derivarse de la interacción con otras culturas y con el sistema jurídico nacional ${ }^{72}$. Asimismo, ha señalado que las comunidades indígenas pueden encontrarse en procesos de "recuperación cultural"73, admi-

69 GUIBOURG, Ricardo. Fuentes del Derecho, ob. cit., p. 182-183.

70 AGUILÓ, Josep. Teoría general de las fuentes del Derecho (y del orden jurídico), ob. cit., p. 94.

71 Ibíd., p. 97

72 Véanse la sentencia de la Corte Constitucional de Colombia T-903/09, fundamento 5.3 y la nota a pie de página 32. El Tribunal Constitucional peruano ha afirmado que "para el caso de los pueblos indígenas, éstos no sólo legitiman sus derechos especiales en virtud de la distinción cultural, sino también por elementos históricos", véase la STC 011262011, fundamento 19 .

73 Corte Constitucional de Colombia, sentencia T-514/09, fundamento 4.3 . tiendo calificar como prácticas indígenas a las “nuevas formas jurídicas adoptadas por la comunidad en su interacción con otras culturas y con el sistema jurídico nacional"74.

No son pocas las dificultades que plantea la pérdida de la cultura tradicional, a lo que se suma la naturaleza esencialmente dinámica de las culturas pues, a falta de aquella, los criterios para calificar a una práctica indígena como fuente del derecho pueden ser algo difusos. El tema no es trivial ya que las autoridades indígenas tienen el poder de imponer las prácticas que regulan la vida de la comunidad y de resolver conflictos invocándolas.

Por ello, parece razonable exigir algunos requisitos mínimos para que las prácticas indígenas puedan ser consideradas fuentes del derecho en el Estado constitucional: a) debe tratarse de prácticas repetidas en el tiempo por una determinada comunidad ${ }^{75}$, b) deben ser identificables y percibidas como obligatorias o exigibles por la comunidad indígena y c) deben ser coherentes con los principios constitucionales ${ }^{76}$.

74 Corte Constitucional de Colombia, sentencia T-903/09, nota a pie de página 32.

75 La Corte Constitucional de Colombia, a la par de reconocer que las prácticas indígenas están en reconstrucción, exige que, en resguardo del principio de legalidad, las autoridades indígenas actúen conforme lo han hecho en el pasado, "con fundamento en las tradiciones que sirven de sustento a la cohesión social" y, por lo tanto, señala que una comunidad que carece de "usos y costumbres" no puede ejercer el juzgamiento de sus miembros, véase la sentencia T-514/09, fundamento 5.3 .

76 La Corte Constitucional de Colombia ha establecido que la jurisdicción indígena comporta: a) un elemento humano, que consiste en la existencia de un grupo diferenciable por su origen étnico y por la persistencia diferenciada de su identidad cultural, b) un elemento orgánico, que implica la existencia de autoridades tradicionales que ejerzan una función de control social en sus comunidades, c) un elemento norma- 


\section{IMPORTANCIA DE LA PREOCUPACIÓN POR LA SITUACIÓN DE LAS MUJERES EN LAS COMUNIDADES INDÍGENAS}

\section{A. Prácticas indígenas relativas a la vida de las mujeres}

\author{
A pesar de la diversidad entre los órdenes nor- \\ mativos indígenas, las investigaciones sobre la \\ situación de las mujeres indígenas en América \\ Latina identifican algunas prácticas más o me- \\ nos comunes en relación con ellas, como las si- \\ guientes:
}

i) Las mujeres no suelen ser autoridades y por lo tanto están excluidas de los espacios formales de poder de las comunidades ${ }^{77}$;

tivo, es decir, un sistema jurídico propio que se rija en la respectiva comunidad, conformado a partir de las prácticas y usos tradicionales, tanto en materia sustantiva como procedimental, d) un ámbito geográfico pues la regulación de jurisdicción indígena en el artículo $246^{\circ}$ de la Constitución remite al territorio, y e) el factor de congruencia en virtud del cual el orden jurídico tradicional de las comunidades no puede ser contrario a la Constitución y la ley, véase la sentencia T-552/03, fundamento 4.1. La Corte Suprema peruana ha hecho suyos estos criterios para la configuración de la jurisdicción indígena, véase el Acuerdo Plenario n. ${ }^{\circ} 1-2009 / \mathrm{CJ}-116$, fundamento 2 . No obstante, hay que aclarar que a tenor del artículo $149^{\circ}$ de la Constitución del Perú, las prácticas indígenas podrían, eventualmente, vulnerar la ley pues el único límite fijado es el respeto a los derechos fundamentales de las personas.

77 Véanse: VÁSQUEZ, Dominga. Experiencia de una alcaldesa indígena. En: LANG, Miriam y KUCIA, Anna (comp.). Mujeres indígenas y justicia ancestral, ob. cit., p. 186; BACÁ, Juana. Prevención de la violencia intrafamiliar conjuntamente con autoridades comunales. En: LANG, Miriam y KUCIA, Anna (comp.). Mujeres indígenas y justicia ancestral, ob. cit., p. 193; AYARZA de ARCHIBOLD, Petita. Trabajo de sensibilización de autoridades tradicionales kunas sobre los derechos de las mujeres. En: LANG, Miriam y KUCIA, Anna (comp.). Mujeres indígenas y justicia ancestral, ob. cit., p. 207. La ausencia de mujeres en los cargos y espacios de decisión más altos también se aprecia en las comunidades chiquitanas, ayoredie, aymara y chimané de Bolivia, véase NOSTAS ARDAYA, Mercedes y SANABRIA SALMÓN, Carmen Elena (coinvestigadoras). Detrás del cristal con que se mira: órdenes normativos e interlegalidad. Mujeres quechuas, aymaras, sirionó, trinitarias, chimane, chiquitanas y ayoreas, ob. cit., p. 47, 66, 82, 91, 102 y 109. Esta situación se agrava en el caso de las mujeres quechua ii) Las mujeres tienen grandes dificultades para acceder a la propiedad o herencia de la tierra $^{78}$;

iii) Las mujeres pueden ser desterradas de la comunidad del ex esposo en caso de separa-

por el hecho de que muchas son monolingües y carecen de destrezas políticas, ibíd, p. 109. Por su parte, las mujeres zapotecas de Oaxaca no pueden participar ni ser elegidas en las elecciones locales, véase CHENAUT, Victoria. Género y justicia en la antropología jurídica en México, ob. cit., p. 62. A diferencia de lo señalado, en la comunidad murui, en Colombia, las mujeres ocupan espacios de decisión organizativa, véase REMUY, Bernardita. El rol de las mujeres y la complementariedad en la justicia ancestral murui. En: LANG, Miriam y KUCIA, Anna (comp.). Mujeres indígenas y justicia ancestral, ob. cit., p. 177. La frecuente ausencia de mujeres en los espacios de decisión contrasta con lo que sucede en la comunidad aymara de Puka Orko en Bolivia, donde la filiación de hombres y mujeres a la estructura sindical es obligatoria, véase NOSTAS ARDAYA, Mercedes y SANABRIA SALMÓN, Carmen Elena (coinvestigadoras). Detrás del cristal con que se mira: órdenes normativos e interlegalidad. Mujeres quechuas, aymaras, sirionó, trinitarias, chimane, chiquitanas y ayoreas, ob. cit., p. 81 . En algunas comunidades indígenas de la sierra ecuatoriana las mujeres mayores son las encargadas de ejecutar los ortigazos, pero en la medida en que son las guardianas de la identidad y de la cultura y, por tanto, asumen la labor de purificar y corregir el comportamiento a fin de preservar el orden comunitario establecido, véase, LANG, Miriam y KUCIA, Anna. Mujeres indígenas y justicia ancestral, ob. cit., p. 84.

De acuerdo con Norma Vázquez "la participación de las mujeres en los espacios comunitarios para la toma de decisiones está limitada tanto por la carencia de tiempo libre debido a las grandes cargas de trabajo doméstico como por la convicción ideológica (llamada complementariedad) de que la voz femenina no tiene lugar en la vida pública”, véase VÁZQUEZ GARCÍA, Norma. ¿Complementariedad o subordinación? Distintas maneras de entender la relación entre mujeres y hombres en el mundo indígena. En: BERRAONDO, Mikerl (coord.). Pueblos indígenas y derechos humanos. Serie Derechos Humanos, vol. 14. Bilbao: Instituto de Derechos Humanos, Universidad de Duesto, 2006, p. 301.

78 HUARCACHO, Filomena Nina. Justicia comunitaria y género en los ayllus aymaras del departamento de La Paz. En: LANG, Miriam y KUCIA, Anna (comp.). Mujeres indígenas y justicia ancestral, ob. cit., p. 107; BATZIBAL, Juana. Conflictos por herencias de mujeres en la justicia ancestral. En: LANG, Miriam y KUCIA, Anna (comp.). Mujeres indígenas y justicia ancestral, ob. cit., p. 195. El problema de la falta de acceso a la titularidad de la propiedad de la tierra también afecta a las mujeres aymaras y chiquitanas en Bolivia, véase NOSTAS ARDAYA, Mercedes y SANABRIA SALMÓN, Carmen Elena (coinvestigadoras). Detrás del cristal con que se mira: órdenes normativos e interlegalidad. Mujeres quechuas, aymaras, sirionó, trinitarias, chimane, chiquitanas y ayoreas, ob. cit., p. 81, 89 y 108. En el caso de las aymaras, la falta de acceso a la propiedad de la tierra excluye a las mujeres de las estructuras políticas y organizativas de la comunidad. Por eso, las mujeres casadas están privadas de una voz pública, son sus maridos los que las representan en la estructura sindical, en la que participan solo si son viudas, separadas o en ausencia del esposo. Sobre la exclusión de las mujeres de la herencia de la tierra véase también CHENAUT, Victoria. Género y justicia en la antropología jurídica en México, ob. cit., p. 63. 
ción ${ }^{79}$ o pierden el respeto de la familia y de la comunidad en caso de divorcio ${ }^{80}$;

iv) El esposo tiene la prerrogativa de "disciplinar" a su mujer infiel, como mecanismo para restaurar su poder y control en la familia ${ }^{81}$. En algunas comunidades, si una mujer es acusada de infidelidad carece de la oportunidad de defenderse pues se le presume responsable y, por lo tanto, recibe la sanción comunitaria ${ }^{82} \mathrm{o}$ la infidelidad femenina se sanciona más severamente que la masculina ${ }^{83}$;

v) Persisten los matrimonios arreglados para niñas y adolescentes ${ }^{84}$, la venta de niñas con

79 HUARCACHO, Filomena Nina. Justicia comunitaria y género en los ayllus aymaras del departamento de La Paz, ob. cit., p. 107 y 109. También sucede en las comunidades aymara de Bolivia, véase NOSTAS ARDAYA, Mercedes y SANABRIA SALMÓN, Carmen Elena (coinvestigadoras). Detrás del cristal con que se mira: órdenes normativos e interlegalidad. Mujeres quechuas, aymaras, sirionó, trinitarias, chimane, chiquitanas y ayoreas, ob. cit., p. 106.

80 Sucede en las comunidades aymara de Bolivia, véase NOSTAS ARDAYA, Mercedes y SANABRIA SALMÓN, Carmen Elena (coinvestigadoras). Detrás del cristal con que se mira: órdenes normativos e interlegalidad. Mujeres quechuas, aymaras, sirionó, trinitarias, chimane, chiquitanas y ayoreas, ob. cit., p. 131.

81 Ibíd., p. 106 y 136. Es el caso de las mujeres quechua, en Bolivia. Sobre la práctica del esposo de disciplinar a su mujer véase también HERNÁNDEZ CASTILLO, Aída. El derecho positivo y la costumbre jurídica: las mujeres indígenas de Chiapas y sus luchas por el acceso a la justicia, ob. cit., p. 11.

82 PEQUEÑO, Andrea. Violencia de género y mecanismos de resolución comunitaria en comunidades indígenas de la sierra ecuatoriana, ob. cit., p. 86. En las comunidades quechua y aymara de Bolivia también se advierte un mayor reproche a la infidelidad femenina que a la masculina, véase NOSTAS ARDAYA, Mercedes y SANABRIA SALMÓN, Carmen Elena (coinvestigadoras). Detrás del cristal con que se mira: órdenes normativos e interlegalidad. Mujeres quechuas, aymaras, sirionó, trinitarias, chimane, chiquitanas y ayoreas, ob. cit., p. 105.

NOSTAS ARDAYA, Mercedes y SANABRIA SALMÓN, Carmen Elena (coinvestigadoras). Detrás del cristal con que se mira: órdenes normativos e interlegalidad. Mujeres quechuas, aymaras, sirionó, trinitarias, chimane, chiquitanas y ayoreas, ob. cit, p. 132

84 Véanse GUAMÁ, Lucy; PANCHO, Avelina y REY Elena. Antigua era más duro: hablan las mujeres indígenas de Antioquia, ob. cit., p. 55, 70-71 y 123; y NOSTAS ARDAYA, Mercedes y SANABRIA SALMÓN, Carmen Elena (coinvestigadoras). Detrás del cristal con que se mira: fines matrimoniales ${ }^{85}$, así como la expulsión de la mujer que se casa con alguien ajeno a la comunidad, lo que conlleva la pérdida de la propiedad del terreno heredado del padre ${ }^{86}$;

vi) En casos de violación sexual el daño se repara mediante la promesa de matrimonio o el pago de una suma de dinero ${ }^{87}$;

vii) Hay un deber de obediencia de las mujeres a los requerimientos sexuales del marido ${ }^{88} \mathrm{y}$ una obligación de que las viudas se casen solo con viudos ${ }^{89}$

órdenes normativos e interlegalidad. Mujeres quechuas, aymaras, sirionó, trinitarias, chimane, chiquitanas y ayoreas, ob. cit., p. 49. Esta práctica existe en los pueblos chiquitano, trinitario y ayoreo, ibíd., p. 86, 88 y 96. Véanse también HERNÁNDEZ CASTILLO, Aída. El derecho positivo y la costumbre jurídica: las mujeres indígenas de Chiapas y sus luchas por el acceso a la justicia, ob. cit., p. 42; CHENAUT, Victoria. Género y justicia en la antropología jurídica en México, ob. cit., p. 62 y ALTO COMISIONADO DE LAS NACIONES UNIDAS PARA LOS DERECHOS HUMANOS. El derecho a una vida libre de discriminación y violencia: mujeres indígenas de Chiapas, Guerrero y Oaxaca, México, D. F., 2007, p. 115-116.

85 Es lo que ocurre en comunidades indígenas triquis asentadas en el Distrito Federal, así como en comunidades indígenas de Oaxaca y Guerrero, véase el Boletín Informativo sobre Derechos Humanos de Mujeres y Equidad de Género, Mujeres News, octubre 2012, año 6, n. ${ }^{\circ}$ 65.

86 LÓPEZ SANTIZ, Rosa. La defensa de mujeres indígenas en Chiapas. En: LANG, Miriam y KUCIA, Anna (comp.). Mujeres indígenas y justicia ancestral, ob. cit., p. 214.

87 NOSTAS ARDAYA, Mercedes y SANABRIA SALMÓN, Carmen Elena (coinvestigadoras). Detrás del cristal con que se mira: órdenes normativos e interlegalidad. Mujeres quechuas, aymaras, sirionó, trinitarias, chimane, chiquitanas y ayoreas, ob. cit., p. 139. A diferencia de lo señalado, en la región de Cachachi, en Bolivia, se ha identificado que la violación sexual y el incesto se sancionan con penas severas, generalmente la expulsión de la comunidad, ibíd., p. 138. Véase también HERNÁNDEZ CASTILLO, Aída. El derecho positivo y la costumbre jurídica: las mujeres indígenas de Chiapas y sus luchas por el acceso a la justicia, ob. cit., p. 39.

88 Es el caso de las mujeres de las comunidades chiquitana y quechua en Bolivia. Véase NOSTAS ARDAYA, Mercedes y SANABRIA SALMÓN, Carmen Elena (coinvestigadoras). Detrás del cristal con que se mira: órdenes normativos e interlegalidad. Mujeres quechuas, aymaras, sirionó, trinitarias, chimane, chiquitanas y ayoreas, ob. cit., p. 89 y 106.

89 Esta regla existe en los pueblos chiquitano y trinitario de Bolivia, ibíd., p. 87 y 88 . 
viii) No hay una respuesta adecuada frente a los casos de violencia intrafamiliar; estos no llegan al cabildo o a la asamblea para su atención, más bien deben ser tratados en el ámbito doméstico. Esta forma de violencia es considerada como "un asunto menor que, cuando no se calla, se resuelve al interior de las familias"90;

ix) Se recurre a la conciliación como mecanismo de resolución de los casos de violencia familiar, la que sirve para reforzar estereotipos de género ${ }^{91}$;

x) Hay obligación de que las mujeres usen la

90 Ibíd., p. 85. Véase también ZOLEZZI, Graciela. El ejercicio de los derechos de las mujeres en los pueblos indígenas de las tierras bajas de Bolivia. En: LANG, Miriam y KUCIA, Anna (comp.). Mujeres indígenas y justicia ancestral, ob, cit., p. 96-97; YARABI, Claribel. El fortalecimiento de las mujeres en torno a la violencia de género en Pando. En: LANG, Miriam y KUCIA, Anna (comp.). Mujeres indígenas y justicia ancestral, ob. cit., p. 155; YAGKIKAT, Elva Rosa. Los derechos de las mujeres en la justicia ancestral awajún. En: LANG, Miriam y KUCIA, Anna (comp.). Mujeres indígenas y justicia ancestral, ob. cit., p. 164; GUAMÁ, Lucy; PANCHO, Avelina y REY, Helena. Antigua era más duro: hablan las mujeres indígenas de Antioquia, ob. cit., p. 178 y 191. En esta última publicación se afirma que, en varios casos de violencia contra las mujeres, el castigo no pasa de una sanción económica o de trabajo comunitario, en otros se ha aplicado el cepo, la cárcel o ha habido una inspección de la policía no indígena. En los pueblos sirionó y ayoreode, en Bolivia, los casos que tienen que ver con problemas en la pareja son generalmente atendidos en el ámbito familiar, véase NOSTAS ARDAYA, Mercedes y SANABRIA SALMÓN, Carmen Elena (coinvestigadoras). Detrás del cristal con que se mira: órdenes normativos e interlegalidad. Mujeres quechuas, aymaras, sirionó, trinitarias, chimane, chiquitanas y ayoreas, ob. cit., p. 135 y 147.

Ibíd., p. 137. Ocurre en las comunidades quechua, en Bolivia. En los casos de violencia en la pareja, las autoridades del pueblo trinitario reprenden al marido haciendo referencia al significado del compromiso matrimonial ante Dios, a la obligación de la mujer de no abandonar el hogar y a la del hombre de tratar bien a la esposa, ibíd., p. 134. Véase también HERNÁNDEZ CASTILLO, Aída. El derecho positivo y la costumbre jurídica: las mujeres indígenas de Chiapas y sus luchas por el acceso a la justicia, ob. cit., p. 39 y 41 . El refuerzo de roles de género a través de las actas de conciliación, en los casos de denuncias de mujeres, también sucede en las comunidades totonaca de Veracruz y nahua de la Sierra Norte de Puebla, véase CHENAUT, Victoria. Género y justicia en la antropología jurídica en México, ob. cit., p. 61. Sobre este tema también puede consultarse el trabajo de Jane F. COLLIER, en el que hace referencia a los zinacantecos en México, véase Problemas teórico-metodológicos en la antropología jurídica. En: CHENAUT, Victoria y SIERRA, María Teresa (coords.). Pueblos indígenas ante el Derecho, ob. cit., p. 56-57. vestimenta tradicional, a diferencia de los hombres que pueden abandonarla, sin mayor cuestionamiento de la comunidad ${ }^{92}$;

xi) Las mujeres suelen ser, con más frecuencia que los hombres, monolingües, lo que se convierte en una limitación cuando salen de las comunidades ${ }^{93} \mathrm{o}$ acuden a un centro de salud ${ }^{94}$.

De acuerdo con Vázquez "en la medida en que el respeto a la naturaleza forma parte de la tradición indígena, las relaciones actuales de género se explican como parte de un orden natural predeterminado que no se puede ni debe alterar porque forma parte de una armonía cósmica a la que el ser humano se debe integrar"95.

\section{B. Derechos colectivos, diálogo intercultural y derechos de las mujeres}

92 VÁZQUEZ GARCÍA, Norma. ¿Complementariedad o subordinación? Distintas maneras de entender la relación entre mujeres y hombres en el mundo indígena, ob. cit., p. 303-304. Esta autora afirma que uno de los símbolos más firmes de la cultura es la vestimenta, por ello en las comunidades se cuestiona cuando las mujeres deciden no usar la ropa tradicional, pues se considera que precisamente las encargadas de transmitir los valores culturales ponen en peligro la preservación de la cultura. Esta autora relata que, incluso, en un evento en la ciudad de Bilbao, en invierno, las mujeres indígenas usaban su vestimenta, que incluía zapatos no apropiados para el frío, a diferencia de los hombres que tenían zapatos con suela ancha.

93 Ibíd., p. 304. Jane Collier afirma que la necesidad de los miembros de movimientos nacionalistas de reivindicar tradiciones únicas crea una presión contradictoria para distinguir entre hombres racionales y mujeres tradicionales. "Ello se evidencia, en Zinacantán (México) pues a diferencia de lo que ocurría en 1960, en 1995 los hombres hablaban español y en su mayoría usaban vestimentas ladinas cuando trabajaban o viajaban fuera de la comunidad; en cambio, las mujeres seguían siendo monolingües y usaban vestido tradicional donde quiera que fueran", véase Jane F. COLLIER. Problemas teórico-metodológicos en la antropología jurídica, ob. cit., p. 71.

94 Véase el Boletín Informativo sobre Derechos Humanos de Mujeres y Equidad de Género, Mujeres News, octubre 2012, año 6, n. ${ }^{\circ} 65$.

95 VÁZQUEZ GARCÍA, Norma. ¿Complementariedad o subordinación? Distintas maneras de entender la relación entre mujeres y hombres en el mundo indígena, ob. cit., p. 295. 
Según Seyla Benhabib, desde que las culturas han interactuado y se han comparado entre sí, de lo que ya hay constancia en la obra de Platón, el estatus de las mujeres y los rituales del sexo, matrimonio y muerte han ocupado un lugar especial en la comprensión intercultural, por lo que no debería sorprender que en nuestros días estos temas provoquen luchas culturales amargas y profundamente divisorias ${ }^{96}$.

Sin embargo, un Estado constitucional no puede reconocer como "jurídicas" aquellas prácticas que colisionan abiertamente con los derechos fundamentales y que "naturalizan" relaciones inequitativas de género. Si bien en América Latina no se puede desconocer la enorme importancia del reconocimiento de los derechos colectivos de las comunidades indígenas (sobre todo como protecciones externas ${ }^{97}$ ), hay que admitir que estas pueden tener prácticas violatorias de los derechos de sus integrantes.

La difusión de los derechos constitucionales y de la categoría "género" en las comunidades indígenas ${ }^{98}$, así como la interacción con el mundo

96 BENHABIB, Seyla. Las reivindicaciones de la cultura. Igualdad y diversidad en la era global. Alejandra Vassallo (trad.). Buenos Aires: Katz, 2006, p. 145-147.

Utilizo la clásica distinción que realiza Will Kymlicka entre dos tipos de reivindicaciones de los grupos étnicos: las protecciones externas y las restricciones internas. Las primeras implican relaciones intergrupales, pues se trata de medidas que tienen por objeto proteger la existencia e identidad del grupo limitando el impacto de las decisiones de la sociedad en la que está englobado. Las segundas comportan relaciones intragrupales y se presentan cuando el poder del grupo étnico se utiliza para restringir la libertad de sus propios miembros, a fin de evitar el disenso interno, véase KYMLICKA, Will. Ciudadanía multicultural. Una teoría liberal de los derechos humanos. Carmé Castells Auleda (trad.). Barcelona: Paidós, 1996, p. 58.

NOSTAS ARDAYA, Mercedes y SANABRIA SALMÓN, Carmen Elena (coinvestigadoras). Detrás del cristal con que se mira: órdenes norma- urbano y el fenómeno de la migración ${ }^{99}$ están contribuyendo a una reconstrucción de la identidad cultural de ciertas mujeres indígenas, quienes reclaman igualdad en las relaciones conyugales, mayor liderazgo en la comunidad o derechos sobre la tierra ${ }^{100}$. Las mujeres indígenas de Antioquia (Colombia) y las aymaras de Bolivia han empezado a utilizar los exámenes médico legales para aportar mayor prueba en las investigaciones de las comunidades ${ }^{101}$, y en Bolivia y México las indígenas acuden a la justicia estatal cuando no encuentran una respuesta eficaz en la justicia comunitaria frente a los casos de violencia familiar y sexual ${ }^{102}$. Siguiendo a Amartya Sen, es posible afirmar que las culturas no necesariamente involucran un conjunto de actitudes y creencias extraordinariamente definidas, sino que más bien contienen considerables variacio-

tivos e interlegalidad. Mujeres quechuas, aymaras, sirionó, trinitarias, chimane, chiquitanas y ayoreas, ob. cit., p. 48 y 66. Véase también CHENAUT, Victoria. Género y justicia en la antropología jurídica en México, ob. cit., p. 54 y 62

99 NOSTAS ARDAYA, Mercedes y SANABRIA SALMÓN, Carmen Elena (coinvestigadoras). Detrás del cristal con que se mira: órdenes normativos e interlegalidad. Mujeres quechuas, aymaras, sirionó, trinitarias, chimane, chiquitanas y ayoreas, ob. cit., p. 83.

100 Ibíd., p. 83.

101 GUAMÁ, Lucy; PANCHO, Avelina y REY, Elena. Antigua era más duro: hablan las mujeres indígenas de Antioquia, ob. cit., p. 195-196 y NOSTAS ARDAYA, Mercedes y SANABRIA SALMÓN, Carmen Elena (coinvestigadoras). Detrás del cristal con que se mira: órdenes normativos e interlegalidad. Mujeres quechuas, aymaras, sirionó, trinitarias, chimane, chiquitanas y ayoreas, ob. cit., p. 148.

102 CHENAUT, Victoria. Género y justicia en la antropología jurídica en México, ob. cit., p. 49 y 61; NOSTAS ARDAYA, Mercedes y SANABRIA SALMÓN, Carmen Elena (coinvestigadoras). Detrás del cristal con que se mira: órdenes normativos e interlegalidad. Mujeres quechuas, aymaras, sirionó, trinitarias, chimane, chiquitanas y ayoreas, ob. cit., p. 131, 138, 139, 140 y 144. Véase también INKSATER, Kimberly. Resolviendo tensiones entre derecho indígena y normas de derechos humanos a través del pluralismo juri-cultural transformativo. Trabajo de investigación, Facultad de Derecho, Universidad de Otawa. Versión original en inglés, 28 de julio de 2006, p. 25-26. 
nes internas, por lo que es posible contemplar diferentes actitudes y creencias dentro de la misma cultura ${ }^{103}$.

Se suele proponer que el tema de los derechos humanos sea tratado en el marco de un diálogo intercultural que contemple contextos culturales, históricos y sociales ${ }^{104}$. En esa misma línea, se afirma que el intérprete constitucional debe "recurrir a un diálogo que le permita entender el punto de vista de una cultura distinta, para ello debe escuchar a los involucrados y auxiliarse además de los conceptos y la indagación empírica de las ciencias sociales, y en especial de la antropología jurídica, en este sentido también hay diálogos de saberes" ${ }^{105}$.

No estoy en contra del diálogo intercultural, de los peritajes antropológicos o de una interpretación de determinados derechos fundamentales que tenga en cuenta la protección de la identidad cultural de las comunidades indígenas. Concuerdo, por ejemplo, en que el contenido del debido proceso en la jurisdicción indígena es distinto al de la justicia ordinaria y, respetando ciertos límites, en que las comunidades indígenas pueden ejercer legítimamente la fuerza. Sin embargo, la interpretación intercultural debe tener límites, entre los que se encuentran los derechos a la dignidad personal, a la liber-

103 SEN, Amartya. Identidad y violencia. La ilusión del destino. Verónica Inés Weinstabl y Servanda María de Hagen (trads.). Madrid: Katz discusiones, junio de 2007, p. 63-64.

104 CHENAUT, Victoria. Género y justicia en la antropología jurídica en México, ob. cit., p. 65.

105 GRIJALBA, Agustín. El estado plurinacional e intercultural en la Constitución ecuatoriana de 2008, ob. cit. p. 157. tad o la igualdad de las mujeres. No debemos olvidar que en el Estado constitucional los derechos fundamentales condicionan el contenido y aplicación de todo el ordenamiento jurídico, lo que incluye el contenido y la aplicación de los órdenes normativos indígenas. Por lo tanto, no se puede pretender validez jurídica para las prácticas indígenas que claramente son incoherentes con los derechos antes mencionados.

La preocupación por la protección de las mujeres indígenas al interior de sus comunidades no es ajena a las constituciones y legislación latinoamericanas. La Constitución de México (artículo $2^{\circ} \mathrm{A}$ II) expresamente señala que la aplicación de los sistemas normativos propios tiene como límite los derechos de las mujeres a la dignidad e integridad. La Constitución de Ecuador establece que la jurisdicción indígena aplicará las tradiciones ancestrales y el derecho propio "con garantía de participación y decisión de las mujeres" (artículo 171) ${ }^{106}$. Otros límites expresamente vinculados a la protección de los derechos de la mujer han sido establecidos en las leyes nacionales, como la Ley Orgánica de Garantías Jurisdiccionales y Control Constitucional de Ecuador y la Ley 073, Ley de Deslinde Jurisdiccional I de Bolivia ${ }^{107}$.

106 La Corte Constitucional de Colombia, en una reciente sentencia dictada a propósito de una contienda de competencia entre la jurisdicción indígena y la ordinaria, que incluye dos casos de violación sexual contra niñas indígenas, resolvió solo uno de ellos a favor de la justicia ordinaria por considerar que "el derecho propio de la comunidad indígena no solo no ofrece la institucionalidad necesaria para garantizar los derechos de la presunta víctima, sino que no cuenta con un mínimo de predecibilidad y previsibilidad que permita suponer que el derecho al debido proceso del acusado será salvaguardado", véase la sentencia T-002-12, fundamento jurídico 2.4.4.

107 En Ecuador, la Ley Orgánica de Garantías Jurisdiccionales y Control Constitucional (2009) señala expresamente que "las juezas o jueces 
Como se ha dicho, el pluralismo jurídico no es incompatible con el Estado constitucional de derecho. Sin embargo, ni las prácticas indígenas ni las decisiones que toman las autoridades de las comunidades indígenas invocándolas deben quedar fuera del control constitucional. Los ejemplos citados de prácticas indígenas en relación con las mujeres constituyen buenas razones para no dar mayor peso, prima facie, a los derechos colectivos de las comunidades indígenas pues estos pueden colisionar abiertamente con los derechos a la dignidad, libertad e igualdad de sus integrantes.

Por lo tanto, cuando las mujeres indígenas consideren que una decisión de las autoridades comunales vulnera sus derechos constitucionales deben tener la posibilidad de cuestionarla a través de procesos de amparo, que pueden llegar hasta el Tribunal Constitucional ${ }^{108}$. La fuerza ex-

deberán impedir que en sentencias de justicia indígena se alegue la costumbre, la interculturalidad o el pluralismo jurídico para violar los derechos humanos o de participación de las mujeres" (artículo 66 inciso14). En Bolivia, la Ley 073 (2010), Ley de Deslinde Jurisdiccional, excluye de la jurisdicción indígena una lista de materias y delitos, como "los delitos contra la integridad corporal de niños, niñas y adolescentes, los delitos de violación, asesinato y homicidio".

108 A diferencia de la Corte Constitucional de Colombia, el Tribunal Constitucional peruano no suele acoger las demandas de los indígenas. Uno de los casos resueltos por el mencionado tribunal fue el de una mujer que presentó una demanda de amparo contra el presidente de una comunidad campesina, solicitando su reincorporación como comunera calificada, demanda que fue declarada improcedente mediante la sentencia STC 2195-2005-PA. También se puede mencionar otro caso, en materia sancionatoria, que fue resuelto mediante STC 00220-2012-PA, que declaró improcedente la demanda, y en el que el Tribunal Constitucional no cita el artículo $149^{\circ}$ de la Constitución sino el artículo $89^{\circ}$, así como el artículo $2^{\circ}$ de la Ley Ley General de Comunidades Campesinas n. ${ }^{\circ} 24656$ ("Las Comunidades Campesinas son organizaciones de interés público, con existencia legal y personería jurídica, integradas por familias que habitan y controlan determinados territorios, ligadas por vínculos ancestrales, sociales, económicos y culturales, expresados en la propiedad comunal de la tierra, el trabajo comunal, la ayuda mutua, el gobierno democrático y el desarrollo de actividades multisectoriales, cuyos fines se orientan a la realización plena de sus miembros y del país"). pansiva de los derechos fundamentales impide admitir, en nombre de la autonomía de las comunidades indígenas y de su tradición y cultura, prácticas incuestionablemente discriminatorias.

\section{Bibliografía}

AGUILÓ, Josep. Teoría general de las fuentes del Derecho (y del orden jurídico). Barcelona: Ariel, 2000.

AGUILÓ, Josep. Sobre la constitución del estado constitucional. En: Doxa, 2001.

AGUILÓ REGLA, Josep. Positivismo y postpositivismo. Dos paradigmas jurídicos en pocas palabras. En: Isabel LINFANTE VIDAL. Interpretación jurídica y teoría del Derecho. Lima: Palestra, 2010.

ALEXY, Robert. Una defensa de la Fórmula de Radbruch. En: Rodolfo VIGO (coord.). La injusticia extrema no es derecho. De Radbruch a Alexy. Buenos Aires: Editorial Fontamara, 2008 , p. 375.

ALTO COMISIONADO DE LAS NACIONES UNIDAS PARA LOS DERECHOS HUMANOS. El derecho a una vida libre de discriminación y violencia: mujeres indígenas de Chiapas, Guerrero y Oaxaca. México, D. F.: ACNUDH, 2007.

ATIENZA, Manuel y RUIZ MANERO, Juan. Las piezas del derecho. Teoría de los enunciados jurídicos. Barcelona: Ariel Derecho, setiembre 1996. 
ATIENZA, Manuel. Argumentación y Constitución

[en línea]. Disponible: http://www2.uah.es/ filder/manuel_atienza.pdf

ARIZA HIGUERA, Libardo y BONILLA MALDONADO, Daniel. Pluralismo jurídico. Bogotá: Siglo del Hombre Editores, Universidad de los Andes, Pontificia Universidad Javeriana, 2007.

AYARZA de ARCHIBOLD, Petita. Trabajo de sensibilización de autoridades tradicionales kunas sobre los derechos de las mujeres. En: Miriam LANG y Anna KUCIA (comp). Mujeres indígenas y justicia ancestral. Quito: UNIFEMRegión Andina, mayo 2009.

BACÁ, Juana. Prevención de la violencia intrafamiliar conjuntamente con autoridades comunales. En: Miriam LANG y Anna KUCIA (comp). Mujeres indígenas y justicia ancestral. Quito: UNIFEM-Región Andina, mayo 2009.

BATZIBAL, Juana. Conflictos por herencias de mujeres en la justicia ancestral. En: Miriam LANG y Anna KUCIA (comp). Mujeres indígenas y justicia ancestral. Quito: UNIFEM-Región Andina, mayo 2009.

BAZÁN SEMINARIO, César. Estado plural de derecho. Bases para una redefinición del concepto Estado de derecho a la luz de la pluralidad jurídica. Lima: Instituto de Defensa Legal, noviembre de 2012.

BERNARDO SANTOS, Roselia. Promoción de la participación de las mujeres en la justicia indígena en Oaxaca. En: Miriam LANG y Anna
KUCIA (comp). Mujeres indígenas y justicia ancestral. Quito: UNIFEM-Región Andina, mayo 2009.

BERRAONDO, Mikerl (coord.). Pueblos indígenas y derechos humanos. Serie Derechos Humanos, vol. 14. Bilbao: Instituto de Derechos Humanos, Universidad de Duesto, 2006.

BENHABIB, Seyla. Las reivindicaciones de la cultura. Igualdad y diversidad en la era global. Alejandra Vassallo (trad.). Buenos Aires: Katz, 2006, p. 145-147.

BOBBIO, Norberto. Teoría general del derecho. Bogotá: Temis, 1987.

Boletín Informativo sobre Derechos Humanos de Mujeres y Equidad de Género. Mujeres News, octubre 2012, año 6, n. ${ }^{\circ} 65$.

BONILLA MALDONADO, Daniel. Pluralismo jurídico. Bogotá: Siglo del Hombre Editores, Universidad de los Andes, Pontificia Universidad Javeriana, 2007.

CARBONELL, Miguel. El neoconstitucionalismo en su laberinto. En: Miguel CARBONELL (ed.). Teoría del neoconstitucionalismo. Ensayos escogidos. Madrid: Editorial Trotta, Instituto de Investigaciones Jurídicas, UNAM, 2007.

CHENAUT, Victoria y SIERRA, María Teresa (coords.). Pueblos indígenas ante el Derecho. México: Centro de Investigaciones y Estudios Superiores en Antropología Social - Centro Francés de Estudios Mexicanos y Centroamericanos, 1995. 
CHENAUT, Victoria. Género y justicia en la antropología jurídica en México. En: Papeles de Trabajo n. ${ }^{\circ}$ 15, 2007.

COLLIER, Jane F. Problemas teórico-metodológicos en la antropología jurídica. En: Victoria CHENAUT y María Teresa SIERRA (coords.). Pueblos indígenas ante el derecho. México: Centro de Investigaciones y Estudios Superiores en Antropología Social - Centro Francés de Estudios Mexicanos y Centroamericanos, 1995.

CORREAS, Óscar. Teoría del derecho y antropología jurídica. Un diálogo inconcluso. México: Ediciones Coyoacán, 2010.

CORREAS, Óscar. Pluralismo jurídico, alternatividad y derecho indígena. México, D.F.: Fontamara, 2003

CORTE CONSTITUCIONAL DE COLOMBIA, sentencia T-514/09.

CORTE CONSTITUCIONAL DE COLOMBIA, sentencia T-428/92.

CORTE CONSTITUCIONAL DE COLOMBIA, sentencia T-380/93.

CORTE CONSTITUCIONAL DE COLOMBIA, sentencia T-903/09.

CORTE CONSTITUCIONAL DE COLOMBIA, sentencia T-552/03.

CORTE CONSTITUCIONAL DE COLOMBIA, sentencia T-002/12.
CUMES, Aura Estela. Mujeres indígenas, poder y justicia: de guardianas a autoridades en la construcción de culturas y cosmovisiones. En: Miriam LANG y Anna KUCIA (comp). Mujeres indígenas y justicia ancestral. Quito: UNIFEM-Región Andina, mayo 2009.

DEFENSORÍA DEL PUEBLO DE LA CIUDAD DE BUENOS AIRES. Boletín Informativo sobre Derechos Humanos de Mujeres y Equidad de Género Mujeres News, año 6, n. ${ }^{\circ}$ 65, octubre 2012.

DUPRET, Baudouin. Legal Pluralism, Plurality of Laws, and Legal Practices: Theories, Critiques, and Praxiological Re-specification. In: European Journal of Legal Studies Issue, April 2007, 1.

GARZÓN VALDÉS, Ernesto y LAPORTA, Francisco. El derecho y la justicia. Madrid: Editorial Trotta, Consejo Superior de Investigaciones Científicas, 1996.

GUASTINI, Riccardo. La constitucionalización del ordenamiento jurídico: el caso italiano. En: Miguel CARBONELL (ed.). Neoconstitucionalismo(s). Madrid: Editorial Trotta, 2003, p. 49-73.

GUEVARA, Armando. Diversidad y complejidad legal. Aproximaciones a la antropología e historia del Derecho. Lima: Fondo Editorial PUCP, 2009

GUIBOURG, Ricardo. Fuentes del Derecho. En: Ernesto GARZÓN VALDÉS y Francisco LAPOR- 
TA (eds.). El derecho y la justicia. Madrid: Editorial Trotta, Consejo Superior de Investigaciones Científicas, 1996.

GRIFFITHS, John. What is legal Pluralism. Disponible en: keur.eldoc.ub.rug.nl/FILES/wetenschappers/2/11886/11886.pdf

GRIJALBA, Agustín. El estado plurinacional e intercultural en la Constitución ecuatoriana de 2008. En: Raquel YRIGOYEN FAJARDO (editora). Pueblos indígenas. Constituciones y reformas políticas en América Latina. Lima: Instituto Internacional de Derecho y Sociedad, 2010.

GUAMÁ, Lucy; PANCHO, Avelina y REY, Elena. Antigua era más duro: hablan las mujeres indígenas de Antioquia. Colección Autonomía Indígena 3, Centro de Cooperación al Indígena (Cecoin) y Organización Indígena de Antioquia (OIA), Bogotá, 2009.

HART, Herbert. El concepto derecho. Genaro R. Carrió (trad.). México, D. F.: Editora Nacional, 1980.

HERNÁNDEZ CASTILLO, Rosalva Aída. Por los entrecruces del género, la justicia y la legalidad en tierras indígenas. En: Desacatos, enero-abril de 2007, n. $^{\circ} 023$.

HERNÁNDEZ CASTILLO, Aída. El derecho positivo y la costumbre jurídica: las mujeres indígenas de Chiapas y sus luchas por el acceso a la justicia. En: Marta TORRES FALCÓN. VioIencia contra las mujeres en contextos urba- nos y rurales. México: El Colegio de México, Programa Interdisciplinario de Estudios de la Mujer, 2003.

HUARCACHO, Filomena Nina. Justicia comunitaria y género en los ayllus aymaras del departamento de La Paz. En: Miriam LANG y Anna KUCIA (comp). Mujeres indígenas y justicia ancestral. Quito: UNIFEM-Región Andina, mayo 2009.

KELSEN, Hans. Teoría pura del derecho. México D. F.: Editorial Porrúa, 16ª edición, 2009.

KYMLICKA, Will. Ciudadanía multicultural. Una teoría liberal de los derechos humanos. Carmé Castells Auleda (trad.). Barcelona: Paidós, 1996.

INKSATER, Kimberly. Resolviendo tensiones entre derecho indígena y normas de derechos humanos a través del pluralismo juri-cultural transformativo. Trabajo de investigación, Facultad de Derecho, Universidad de Otawa. Versión original en inglés, 28 de julio de 2006.

LANG, Miriam y KUCIA, Anna (comp.). Mujeres indígenas y justicia ancestral. Quito: UNIFEMRegión Andina, mayo 2009.

LINFANTE, Isabel. La teoría de Ronald Dworkin: la reconstrucción del Derecho a partir de los casos. En: Jueces para la democracia, 1999, n. ${ }^{\circ} 36$.

LÓPEZ SANTIZ, Rosa. La defensa de mujeres indígenas en Chiapas. En: Miriam LANG y Anna 
KUCIA (comp.). Mujeres indígenas y justicia ancestral. Quito: UNIFEM-Región Andina, mayo 2009.

MALDONADO, Korinta y TERVEN, Adriana. Los juzgados indígenas de Cuetzalan y Huehuetla. Vigencia y reproducción de los sistemas normativos de los pueblos de la Sierra Norte de Pueblo. Prólogo de François Lartigue. México: CONACYT, CIESAS y CDI, 2008.

MERRY, Sally Engle. Pluralismo jurídico. En: Libardo ARIZA HIGUERA y Daniel BONILLA MALDONADO. Pluralismo jurídico. Bogotá: Siglo del Hombre Editores, Universidad de los Andes, Pontificia Universidad Javeriana, 2007.

NOSTAS ARDAYA, Mercedes y SANABRIA SALMÓN, Carmen Elena (coinvestigadoras). Detrás del cristal con que se mira: órdenes normativos e interlegalidad. Mujeres quechuas, aymaras, sirionó, trinitarias, chimane, chiquitanas y ayoreas. La Paz: Coordinadora de la Mujer, 2009.

ORELLANA H., René. Derecho: ¿qué eres?, ¿dónde estás? Borrador al 29 de mayo de 2001.

PEQUEÑO, Andrea. Violencia de género y mecanismos de resolución comunitaria en comunidades indígenas de la sierra ecuatoriana. En: Miriam LANG y Anna KUCIA (comp). Mujeres indígenas y justicia ancestral. Quito: UNIFEMRegión Andina, mayo 2009.

REMUY, Bernardita. El rol de las mujeres y la complementariedad en la justicia ancestral murui. En: Miriam LANG y Anna KUCIA (comp). Mujeres indígenas y justicia ancestral. Quito: UNIFEM-Región Andina, mayo 2009.

RUBIO CORREA, Marcial. El sistema jurídico. Introducción al Derecho. Sexta edición corregida y aumentada. Colección de textos jurídicos de la Pontificia Universidad Católica del Perú. Lima: Fondo Editorial, 1993.

SÁNCHEZ BOTERO, Esther. Derechos propios. Ejercicio de la jurisdicción especial indígena en Colombia. Bogotá: Procuraduría General de la Nación, Instituto de Estudios del Ministerio Público, segunda edición, 2007.

SANTOS, Boaventura de Sousa. The Law of the Oppressed: The Construction and Reproduction of Legality in Pasargada. In: Law and Society Review, Autumn 1977, vol. 12, n. ${ }^{\circ} 1$.

SANTOS, Boaventura de Sousa. La globalización del derecho. Los nuevos caminos de la regulación y la emancipación. Bogotá: Facultad de Derecho, Ciencias Políticas y Sociales de la Universidad Nacional de Colombia - ILSA, 1998.

SEN, Amartya. Identidad y violencia. La ilusión del destino. Verónica Inés Weinstabl y Servanda María de Hagen (trads.). Madrid: Katz discusiones, junio de 2007.

TAMANAHA, Brian Z. An Analytical Map of Social and Scientific Approaches to the Concept of Law. In: Oxford Journal of Legal Studies, Winter 1995, vol. 15, n. $^{\circ} 4$ 
TAMANAHA, Brian Z. La insensatez del concepto científico social del pluralismo jurídico. En: Libardo ARIZA HIGUERA y Daniel BONILLA MALDONADO. Pluralismo jurídico. Bogotá: Siglo del Hombre Editores, Universidad de los Andes, Pontificia Universidad Javeriana, 2007.

TIBÁN, Lourdes. Desafíos en la construcción de un Estado plurinacional. En: Miriam LANG y Anna KUCIA (comp.). Mujeres indígenas y justicia ancestral. Quito: UNIFEM-Región Andina, mayo 2009.

TICONA COLQUE, Valentín. Políticas públicas del Gobierno boliviano. En: Miriam LANG y Anna KUCIA (comp.). Mujeres indígenas y justicia ancestral. Quito: UNIFEM-Región Andina, mayo 2009.

TORRES FALCÓN, Marta. Violencia contra las mujeres en contextos urbanos y rurales. México: El Colegio de México, Programa Interdisciplinario de Estudios de la Mujer, 2003.

TRIBUNAL CONSTITUCIONAL DEL PERÚ, sentencia recaída en el expediente $\mathrm{N}^{\circ}$ 00220-2012PA.

TRIBUNAL CONSTITUCIONAL DEL PERÚ, sentencia recaída en el expediente $\mathrm{N}^{\circ}$ 033432007-PA.

TRIBUNAL CONSTITUCIONAL DEL PERÚ, sentencia recaída en el expediente $\mathrm{N}^{\circ} 05427$ 2009-PC.

TRIBUNAL CONSTITUCIONAL DEL PERÚ, sentencia recaída en el expediente $N^{\circ}$ 2195-2005-
PA.

TRIBUNAL CONSTITUCIONAL DEL PERÚ, sentencia recaída en el expediente $\mathrm{N}^{\circ}$ 011262011-HC.

URTEAGA Patricia. Sobre el Acuerdo Plenario n. ${ }^{\circ}$ 1-2009/CJ-116. Una mirada desde la antropología jurídica. En: La facultad jurisdiccional de las rondas campesinas. Comentarios al acuerdo plenario de la Corte Suprema que reconoce facultades jurisdiccionales a las rondas campesinas. Lima: IDL, septiembre de 2010.

VÁSQUEZ, Dominga. Experiencia de una alcaldesa indígena. En: Miriam LANG y Anna KUCIA (comp.). Mujeres indígenas y justicia ancestral. Quito: UNIFEM-Región Andina, mayo 2009.

VÁZQUEZ GARCÍA, Norma. ¿Complementariedad o subordinación? Distintas maneras de entender la relación entre mujeres y hombres en el mundo indígena. En: Mikerl BERRAONDO (coord.). Pueblos indígenas y derechos humanos. Serie Derechos Humanos, vol. 14. Bilbao: Instituto de Derechos Humanos, Universidad de Duesto, 2006.

VILLANUEVA FLORES, Rocío. Derecho a la salud, perspectiva de género y multiculturalismo. Lima: Palestra, 2009.

VILLANUEVA FLORES, Rocío. Tensiones constitucionales: el derecho a la diversidad cultural vs. Ios derechos de las víctimas de violencia 
de género. En: La facultad de administrar justicia de las rondas campesinas. Comentarios sobre el Acuerdo Plenario que reconoce facultades jurisdiccionales a las rondas campesinas. Lima: Instituto de Defensa Legal, 2010.

YAGKIKAT, Elva Rosa. Los derechos de las mujeres en la justicia ancestral awajún. En: Miriam LANG y Anna KUCIA (comp.). Mujeres indígenas y justicia ancestral. Quito: UNIFEMRegión Andina, mayo 2009.

YARABI, Claribel. El fortalecimiento de las mujeres en torno a la violencia de género en Pando. En: Miriam LANG y Anna KUCIA (comp.). Mujeres indígenas y justicia ancestral. Quito: UNIFEM-Región Andina, mayo 2009.

YRIGOYEN FAJARDO, Raquel. Pautas de coordinación entre el derecho indígena y el derecho estatal. Guatemala: Fundación Myrna Mack, agosto 1999.

YRIGOYEN FAJARDO, Raquel. A los veinte años del Convenio 169 de la OIT: balance y retos de la implementación de los derechos de los pueblos indígenas de Latinoamérica. En: Raquel YRIGOYEN FAJARDO (ed.). Pueblos indígenas. Constituciones y reformas políticas en América Latina. Lima: Instituto Internacional de Derecho y Sociedad, 2010.

YRIGOYEN FAJARDO, Raquel (editora). Pueblos indígenas. Constituciones y reformas políticas en América Latina. Lima: Instituto Internacional de Derecho y Sociedad, 2010.

ZAPETA, José Ángel. Valores, principios y situación de la justicia maya en Guatemala. En: Miriam LANG y Anna KUCIA (comp.). Mujeres indígenas y justicia ancestral. Quito: UNIFEMRegión Andina, mayo 2009.

ZOLEZZI, Graciela. El ejercicio de los derechos de las mujeres en los pueblos indígenas de las tierras bajas de Bolivia. En: Miriam LANG y Anna KUClA (comp). Mujeres indígenas y justicia ancestral. Quito: UNIFEM-Región Andina, mayo 2009. 